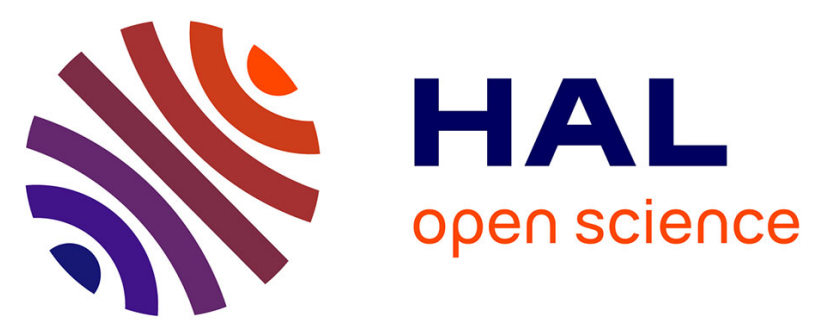

\title{
Tautomerism and electronic spectroscopy of protonated 1- and 2-aminonaphthalene.
}

\author{
Jennifer Anna Noble, Michel Broquier, Gilles Grégoire, Satchin Soorkia, \\ Gustavo Ariel Pino, Ernesto Marceca, Claude Dedonder-Lardeux, Christophe \\ Jouvet
}

\section{To cite this version:}

Jennifer Anna Noble, Michel Broquier, Gilles Grégoire, Satchin Soorkia, Gustavo Ariel Pino, et al.. Tautomerism and electronic spectroscopy of protonated 1- and 2-aminonaphthalene.. Physical Chemistry Chemical Physics, 2018, 20 (9), pp.6134-6145. 10.1039/C8CP00218E . hal-01710813

\section{HAL Id: hal-01710813 \\ https://hal-amu.archives-ouvertes.fr/hal-01710813}

Submitted on 16 Feb 2018

HAL is a multi-disciplinary open access archive for the deposit and dissemination of scientific research documents, whether they are published or not. The documents may come from teaching and research institutions in France or abroad, or from public or private research centers.
L'archive ouverte pluridisciplinaire HAL, est destinée au dépôt et à la diffusion de documents scientifiques de niveau recherche, publiés ou non, émanant des établissements d'enseignement et de recherche français ou étrangers, des laboratoires publics ou privés. 


\title{
Tautomerism and electronic spectroscopy of protonated 1- and 2-aminonaphthalene.
}

\author{
Jennifer A. Noble, ${ }^{\S, 1}$ Michel Broquier, $\#, \not$ Gilles Grégoire, $\#, \not$ Satchin Soorkia,, $\#$ Gustavo Pino,,,$\square$ \\ Ernesto Marceca, ${ }^{*}$ Claude Dedonder-Lardeux, ${ }^{\S}$ Christophe Jouvet. ${ }^{\S, 2}$ \\ ${ }^{\S}$ CNRS, Aix Marseille Université, Physique des Interactions Ioniques et Moléculaires, UMR 7345, 13397, Marseille, France \\ \# CNRS, Univ. Paris-Sud, Université Paris-Saclay, Institut des Sciences Moléculaires d'Orsay (ISMO), F-91405 Orsay, France \\ " Univ. Paris-Sud, CNRS, IOGS, Université Paris-Saclay, Centre Laser de I'Université Paris-Sud (CLUPS/LUMAT), F-91405 Orsay, \\ France \\ ${ }^{\circ}$ INFIQC (CONICET - Universidad Nacional de Cordoba), Ciudad Universitaria, X5000HUA Cordoba, Argentina. \\ $\square$ Dpto. de Fisicoquimica, Facultad de Ciencias Quimicas, Universidad Nacional de Córdoba, Ciudad Universitaria, X5000HUA \\ Cordoba, Argentina and Centro Laser de Ciencias Moleculares, Universidad Nacional de Cordoba, Ciudad Universitaria, \\ X5000HUA Cordoba, Argentina. \\ * INQUIMAE (CONICET - Universidad de Buenos Aires), DQIAQF - Facultad de Ciencias Exactas y Naturales, Universidad de \\ Buenos Aires, Ciudad Universitaria, 3er piso, Pab. II, 1428 Buenos Aires, Argentina.
}

\section{Abstract}

Experimental and theoretical investigations of the excited states of protonated 1- and 2aminonaphthalene are presented. The electronic spectra are obtained by laser induced photofragmentation of the ions captured in a cold ion trap. Using ab-initio calculations, the electronic spectra can be assigned to different tautomers which have the proton on the amino group or on the naphthalene moiety. It is shown that the tautomer distribution can be varied by changing the electrospray source conditions, favoring either the most stable form in solution (amino protonation) or that in the gas phase (aromatic ring protonation). Calculations for larger amino-polyaromatics predict that these systems should behave as "proton sponges" i.e. have a proton affinity larger than $11 \mathrm{eV}$.

\footnotetext{
${ }^{1}$ Present address : Univ. Lille, CNRS, UMR 8523 - PhLAM - Physique des Lasers Atomes et Molécules, F-59000 Lille, France.

${ }^{2}$ corresponding author: christophe.jouvet@univ-amu.fr
} 


\section{Introduction}

Cold ion traps have become very useful tools to study the properties of protonated molecules. In most of the studies published to date, only one tautomer is produced by the combination of an electrospray source and ion traps, leading to the investigation of only the most stable gas phase conformers ${ }^{1-3}$. Only in a few cases have several tautomers been observed and clearly discriminated by their IR (vibrational) ${ }^{4}$ or UV (electronic) spectroscopy, ${ }^{5,6}$, or, more often, by ion mobility ${ }^{7,8}$ or differential ion mobility spectrometry (DIMS) ${ }^{9}$. In addition, a solvent effect on the protonation site has been demonstrated in the case of benzoic acid by a combination of IR spectroscopy and ion mobility ${ }^{10}$. In recent studies on deprotonated $\mathrm{p}$ hydroxybenzoic acid produced in an electrospray source, it has been demonstrated that the observation of one or the other tautomer depends on source parameters such as the temperature of the capillary or the distance between needle and capillary, all these parameters being apparatus and experimentalist dependent ${ }^{11,12}$. Similarly, using DIMS it has recently been demonstrated that the structure of the protonated guanine-cytosine complex (Watson-Crick versus Hoogsteen) can be easily selected by changing the $\mathrm{pH}$ of the solution, which implies that, in this case, the solution phase structure is conserved ${ }^{9}$.

While IR spectra can easily distinguish between protonation sites on N/O or N/C atoms ${ }^{13-15}$, differentiating protonation sites on different carbon atoms of a substituted polycyclic aromatic molecule is much less straightforward. Neither is it evident that traditional ion mobility experiments can separate such tautomers, although more recent techniques such as DIMS seem to be powerful discriminators ${ }^{9}$. Electronic spectroscopy is another alternative, coupling recently developed cold ion traps with ab-initio packages, which can calculate the excited states with reasonable accuracy. For substituted molecules with a single aromatic ring, like aminophenol or purine DNA bases, ${ }^{16}$ it has been shown that electronic spectroscopy can serve to convincingly assign the experimental spectra to different tautomers. The development of UV/UV hole burning spectroscopy in cold traps has added a further tool that can be used to differentiate tautomers. $^{17-19}$

In the present paper, we have studied protonated 1-and 2-aminonaphthalene with the aim of answering the following questions: 
1) How does the proton affinity of polycyclic aromatic hydrocarbons (PAHs) change when a $-\mathrm{NH}_{2}$ substituent is added? In particular, we will compare aminonaphthalene and naphthalene $e^{20}$. In previous studies on aniline, competition between protonation on the amino group ${ }^{15,21,22}$ and on one carbon atom of the ring has been observed. For larger PAHs, however, it is reasonable to expect that the proton affinity will increase with the size of the molecule, and this will favor protonation on a carbon atom of the aromatic moiety. This has been already investigated for aminopyrene ${ }^{23}$, and the calculations tend to show that protonation on a carbon atom of the aromatic skeleton is preferred.

2) In previous studies, we have shown that the excited states dynamics of many amino aromatic systems protonated on the amino group, in particular the amino acids tyrosine, tryptophan and phenylalanine, are influenced by a $\pi \sigma^{*}$ state dissociative along the $\mathrm{NH}$ coordinate ${ }^{24-30}$. We have recently proposed a simple model to estimate the energy of such $\pi \sigma^{*}$ states in amino substituted aromatic molecules based on the ionization potential of the aromatic moiety and the electronic affinity of the protonated amino substituent, which has been shown to remain unchanged as the PAH size increases ${ }^{23}$. Can we evidence the presence of such a state in protonated aminonaphthalene and, if so, is its energy in agreement with the model? We also consider whether the proton affinity of the amino group is influenced by the size of the nearby aromatic part.

3) In protonated naphthalene and larger PAHs, the lowering of the excited state energy in comparison to that of the neutral molecule was assigned to the presence of charge transfer (CT) states ${ }^{31}$. Are CT states also important in aminonaphthalene protonated on a carbon atom of the aromatic skeleton or on the amino group?

In addition, we present a method that allows modification of the distribution of protonated tautomers produced in the electrospray source (ESI), providing an alternative to methods such as hole burning spectroscopy in facilitating the assignment of the electronic transitions. 


\section{Experimental and computational methods.}

The electronic spectra of protonated 1- and 2-aminonaphthalene (denoted 1-ANpH ${ }^{+}$and 2$\mathrm{ANpH}^{+}$) were obtained via ion photo-fragmentation spectroscopy in a cryogenically-cooled Paul trap. The set-up has been extensively described elsewhere ${ }^{6}$ and is similar to those developed in various research groups ${ }^{19,32-36}$ based on the original concept of Wang and Wang ${ }^{19,37-39}$. Protonated ions are produced in an electrospray source ${ }^{40}$, pass through a heated capillary followed by a skimmer in a first chamber, and are then trapped in an octopole. The ions are extracted in bunches from the octopole but this process does not empty the trap and so the ions stay an average of $10 \mathrm{~s}$ in the octopole. After extraction from the octopole, the ions are accelerated to a third chamber ( $p=10^{-5}$ mbar) using pulsed voltages (200 V), producing ion packets of $0.5 \mu$ s to $1 \mu$ s temporal width. The ions are guided towards the Paul trap with electrostatic lenses and deviation plates and decelerated to $5 \mathrm{eV}$ before entering the trap. Under these conditions we do not observe collision-induced fragmentation. The ions are trapped for several tens of $\mathrm{ms}$, and during this period they are thermalized to a temperature of around $50 \mathrm{~K}$ through collisions with cold helium buffer gas, which is constantly removed by pumping. The temperature of the ions in a previous study on protonated acridine was estimated as $40 \pm 10 \mathrm{~K}$ using the intensity of some hot bands (see supplementary information in EstevezLòpez et al. ${ }^{41}$ ). The major difference compared to previous studies is the development of a technique to modify the tautomer distribution in the octopole. The pressure at the exit of the capillary $(1 \mathrm{mbar})$ and in the octopole $\left(10^{-3} \mathrm{mbar}\right)$ can be increased by a factor of ten by changing the pumping speed of the primary pump (pump in standby mode, for example).

Photodissociation of the trapped ions is accomplished with a tunable OPO laser (EKSPLA), which has a $10 \mathrm{~Hz}$ repetition rate, $10 \mathrm{~ns}$ pulse width, a spectral resolution of $\sim 10 \mathrm{~cm}^{-1}$ and a minimum scanning step of $0.02 \mathrm{~nm}$. The laser is shaped to a $1 \mathrm{~mm}^{2}$ spot to fit the entrance hole of the trap and the laser power is around $2 \mathrm{~mJ} /$ pulse in the UV spectral region. The parent and fragment ions are extracted after each laser shot. The parent and photofragment ions are separated in a $1.5 \mathrm{~m}$ time-of-flight mass spectrometer and detected using a microchannel plates (MCP) detector. The spectra are recorded by detecting simultaneously all the ion signals as a function of the excitation energy. 
$A b$ initio calculations were performed with the TURBOMOLE (V6.6) package ${ }^{42}$, making use of the resolution-of-the-identity (RI) approximation for the evaluation of the electron-repulsion integrals $^{43-45}$. The equilibrium geometry of ground state $\left(\mathrm{S}_{0}\right) \mathrm{ANpH}^{+}$was determined at the MP2 and DFT/B3-LYP (density functional theory using the B3-LYP hybrid functional) levels. Complementary calculations have been performed with the MP4 and $\operatorname{CCSD}(T)$ methods. Adiabatic excitation energies of the lowest excited singlet states were determined at the RI-CC2 and TD-DFT levels. Calculations were performed with the correlation-consistent polarized valence double-zeta (cc-pVDZ and aug-cc-pVDZ for $\pi \sigma^{*}$ states) basis set ${ }^{46}$. Ground and excited state vibrations were calculated, and the electronic spectrum was simulated using PGOPHER software $^{47}$ for Franck-Condon analysis.

\section{RESULTS}

\section{ANpH+ photofragmentation spectroscopy}

The full photofragmentation spectra of $1-\mathrm{ANpH}^{+}$and 2- $\mathrm{ANpH}^{+}$recorded over the energy range from the visible to the UV are presented in figures $1 a$ and $1 b$, showing different band systems and different fragmentation channels with branching ratios dependent on the excitation energy. It should be noted that these complicated spectra originate from the presence of several tautomers that will be assigned in the following discussion. 

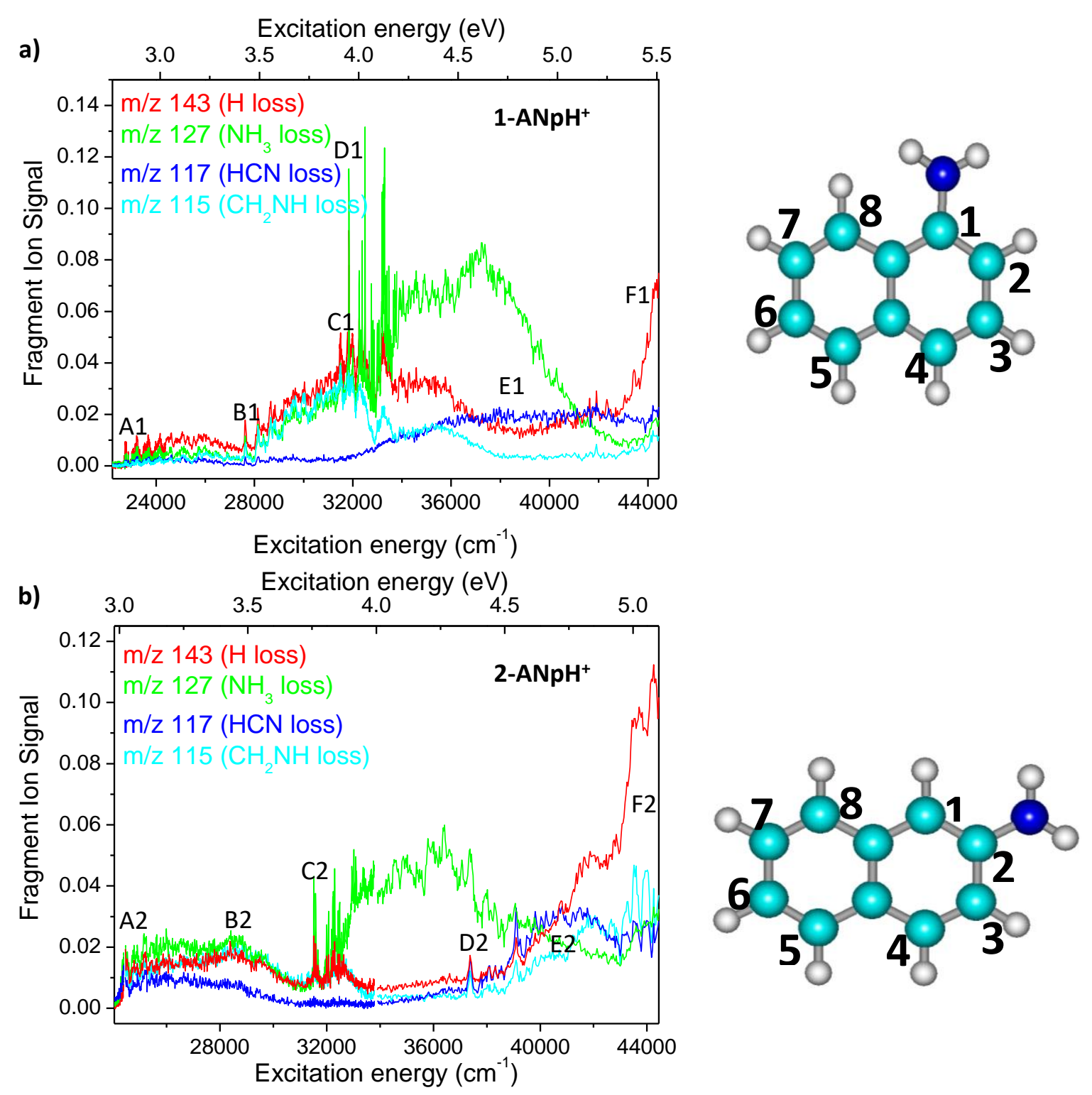

Figure 1 : Photofragmentation spectra of a) 1-ANpH and b) 2-ANpH over the $22000-44440 \mathrm{~cm}^{-1}$ energy region. The different band systems are marked by letters. The 1- and 2-ANp molecules are depicted on the right side with the carbon atom numbering.

The four fragment ion channels presented are those of $\mathrm{m} / \mathrm{z} 143,127,117$ and $115 . \mathrm{H}$ and $\mathrm{NH}_{3}$ loss channels, corresponding to $\mathrm{m} / \mathrm{z} 143$ and $\mathrm{m} / \mathrm{z} 127$ fragment ions, are usual fragmentation channels for protonated aromatic amines. The fragment at $\mathrm{m} / \mathrm{z} 117$ corresponds to the HCN loss channel and is not present in monocyclic amines but is observed in low energy collision experiments of protonated aminopyridine ${ }^{48}$ and diazine ${ }^{49}$, where a proton transfer reaction to a carbon atom of the aromatic ring is the rate limiting step of the HCN loss. The $\mathrm{m} / \mathrm{z}$ 
115 fragment is the major fragment from the radical cation $(\mathrm{m} / \mathrm{z} 143)^{50}$ and it seems to follow the same trends as the $\mathrm{H}$ loss channel. The $\mathrm{m} / \mathrm{z} 103$ fragment ion, which is a secondary fragment of the $\mathrm{m} / \mathrm{z} 127$ ion (see below) has not been plotted in figure 1 .

One can see that the fragment yield changes with the photon energy, in particular in the higher energy region, where the $\mathrm{H}$ loss channel becomes the most prominent channel. For each species, six band systems (labeled A-F) are identified in the photofragmentation spectrum.

\section{Lower energy region (visible)}

The low energy parts of the spectra are presented in figure 2. No signal was observed for lower photon energies.
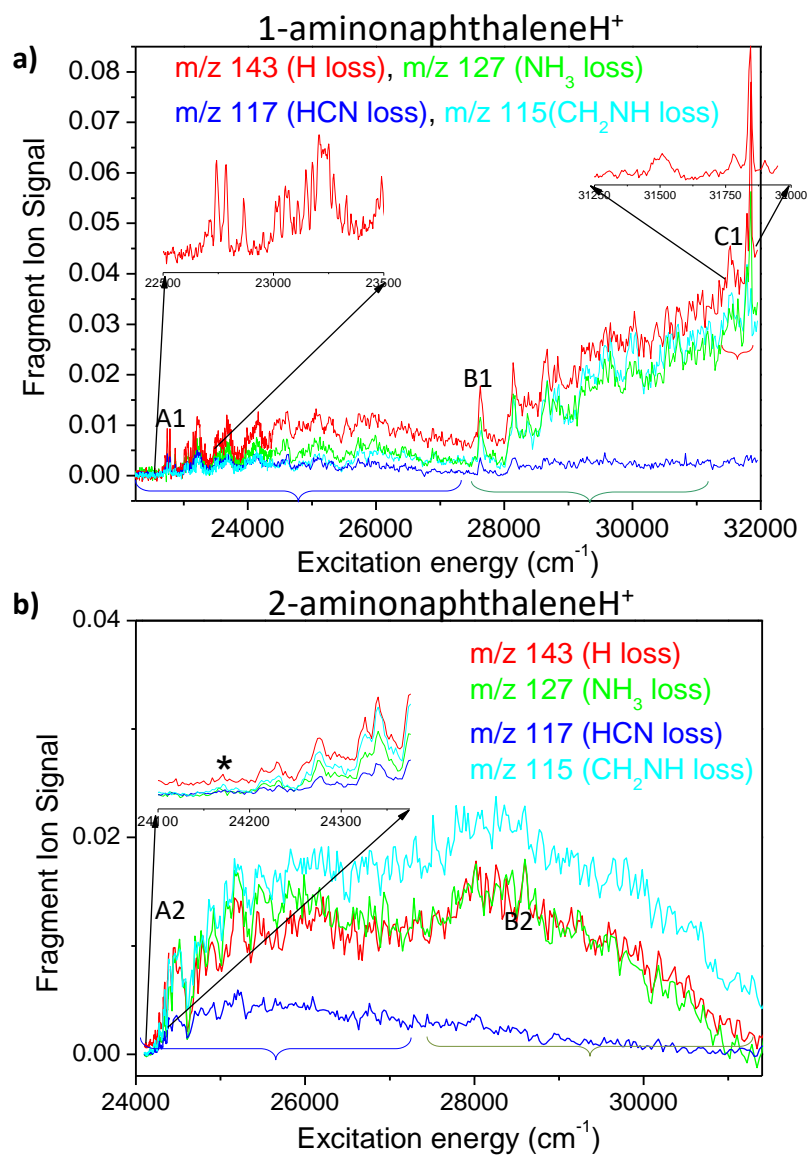

Figure 2 : Photofragmentation spectra over the 23000-32000 $\mathrm{cm}^{-1}$ (3-4 eV) energy region: 1-ANpH (upper panel) and 2-ANpH (lower panel). The different band systems are labeled by letters. Each color corresponds to a specific fragment as indicated in the figure. In the insert the band origins of the first systems are magnified. 


\section{1- $\mathrm{ANpH}^{+}$}

In the lower energy region, between 22500 and $31800 \mathrm{~cm}^{-1}(2.8-3.94 \mathrm{eV})$, the photofragmentation spectrum of $1-\mathrm{ANpH}^{+}$shows three band systems (figure 2 upper panel), although their intensities are much weaker than those of the band system D1 starting at 31840 $\mathrm{cm}^{-1}$ (which will be described in the next section). The lowest energy band system A1 starts in the visible at $22710 \mathrm{~cm}^{-1}(2.82 \mathrm{eV} / 440.3 \mathrm{~nm})$ and presents a complex band structure (left inset) with a branching ratio around $1 / 2 / 3 / 3$ for the different fragmentation channels $\mathrm{m} / \mathrm{z}=115 / 117 / 127 / 143$ (see figure SI-1 in the Supplementary Information). The second band system B1 starts at $27625 \mathrm{~cm}^{-1}(3.42 \mathrm{eV})$ and shows broadened vibronic bands. When exciting this band system the major fragmentation channel is $\mathrm{H}$ loss, and the $\mathrm{m} / \mathrm{z} 117$ fragment (HCN loss) is very low. The third system C1 (right inset) starts at $31500 \mathrm{~cm}^{-1}(3.91 \mathrm{eV})$, and only two bands can be clearly observed, the rest of the band system being buried under the strong D1 system starting at $31840 \mathrm{~cm}^{-1}(3.95 \mathrm{eV})$.

$2 \mathrm{ANpH}^{+}$

Compared to 1- $\mathrm{ANpH}^{+}$, the photofragmentation spectrum of 2- $\mathrm{ANpH}^{+}$in the low energy region shows fewer band structures. Two systems may be distinguished: the first one, $A 2$, starts at $24170 \mathrm{~cm}^{-1}(3.0 \mathrm{eV})$ and shows a few vibronic structures, while the band structure intensities (see insert) may indicate that the band origin is not observed. A second unstructured system, $B 2$, is centered around $29000 \mathrm{~cm}^{-1}(3.60 \mathrm{eV})$, and does not yield the $\mathrm{m} / \mathrm{z} 117$ (HCN loss) fragment.

\section{Structured band systems in the UV region around $32000 \mathrm{~cm}^{-1}$}

The photofragmentation spectra in the UV region around $32000 \mathrm{~cm}^{-1}(4 \mathrm{eV})$ are presented in figure 3. 

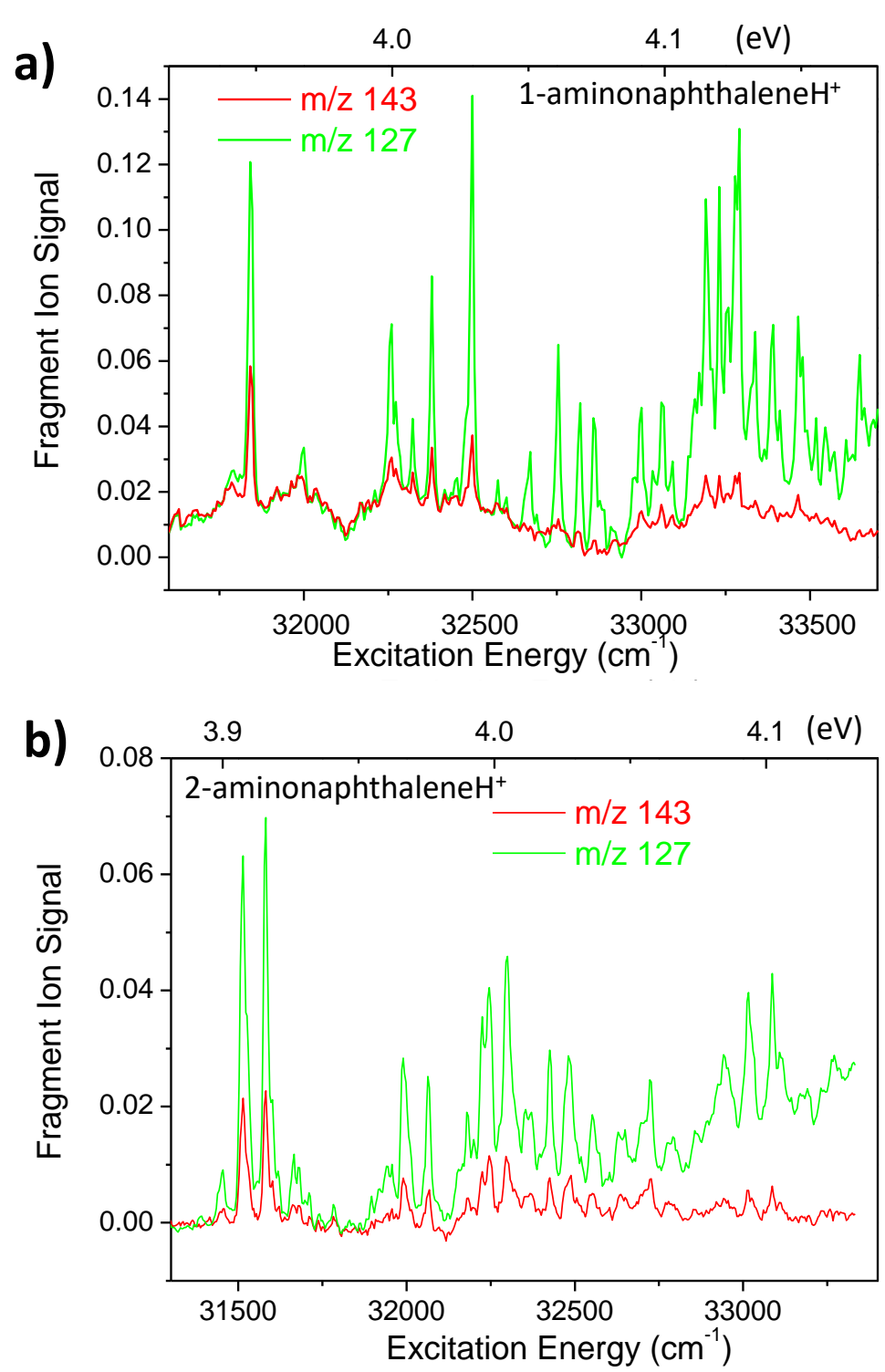

Figure 3: Photofragmentation spectra of 1-ANpH (a) and 2-ANpH $\mathrm{Al}^{+}$(b) in the $32000 \mathrm{~cm}^{-1}$ energy region.

\section{1-ANpH+}

The major band system in protonated 1-ANpH ${ }^{+}, \mathrm{D} 1$, starts at $31840 \mathrm{~cm}^{-1}(3.95 \mathrm{eV})$ and presents narrow vibronic bands for which $\mathrm{H}$ loss and $\mathrm{NH}_{3}$ loss are the major fragments (figure 3a), while these bands are absent when detecting the $\mathrm{m} / \mathrm{z} 117$ fragment, and weak when detecting the $\mathrm{m} / \mathrm{z} 115$ fragment. In addition, the branching ratio between $\mathrm{H}$ loss and $\mathrm{NH}_{3}$ loss channels changes with the excitation energy, being 0.4 on the band origin and 0.15 at $33500 \mathrm{~cm}^{-}$ 
1. The bandwidths are $10 \pm 2 \mathrm{~cm}^{-1}$, and are limited by the laser width. The background underlying the bands is the continuation of the B1 and $\mathrm{C} 1$ band systems.

\section{2-ANpH+}

The equivalent band system in protonated 2- $\mathrm{ANpH}^{+}$(figure $\left.3 \mathrm{~b}\right)$ starts at $31454 \mathrm{~cm}^{-1}(3.90$ $\mathrm{eV}$ ), and shows activity on a low frequency mode (c.a. $60 \mathrm{~cm}^{-1}$ ) that was absent in 1-ANpH $\mathrm{H}^{+}$The fragmentation pattern is the same as for $1-\mathrm{ANpH}^{+}$, with a branching ratio between $\mathrm{H}$ loss and $\mathrm{NH}_{3}$ loss channels ranging from 0.33 at the band origin to 0.15 at $33100 \mathrm{~cm}^{-1}$.

\section{High energy region 34000-44000 $\mathrm{cm}^{-1}(4.2-5.5 \mathrm{eV})$}

This spectral region is presented in figure 1.

\section{$1-\mathrm{ANpH}^{+}$}

For $1-\mathrm{ANpH}^{+}$there is a broad continuum, particularly well defined on the $\mathrm{NH}_{3}$ and $\mathrm{HCN}$ loss channels (E1 figure 1a), starting around $32000 \mathrm{~cm}^{-1}(4.0 \mathrm{eV})$ and centered around $36000 \mathrm{~cm}^{-1}$ (4.46 eV). Finally, there is an increase in the signal recorded only on the $\mathrm{H}$ loss channel (F1) above $42000 \mathrm{~cm}^{-1}(5.20 \mathrm{eV})$, which may be the beginning of another band.

\section{2-ANpH+}

For $2-\mathrm{ANpH}^{+}$there is also a broad continuum (system E2) starting around $34000 \mathrm{~cm}^{-1}(4.20$ $\mathrm{eV}$ ) and centered around $41000 \mathrm{~cm}^{-1}(5.10 \mathrm{eV})$, with a few narrow bands superimposed on this continuum (system D2 in figure $1 \mathrm{~b}$ ) and particularly well defined on the $\mathrm{H}$ and HCN loss channels. Finally, there is an increase in the signal recorded only on the $\mathrm{H}$ loss channel (F2) above $42000 \mathrm{~cm}^{-1}(5.20 \mathrm{eV})$, which, as for $1-\mathrm{ANpH}^{+}$, may be the beginning of another band.

\section{Additional experiments}

Hole burning experiments have been performed to determine whether different tautomers were responsible for the observed band systems. Such experiments consist of setting the pump frequency and the probe frequency to known absorption bands in the spectrum, with depletion in the fragment signal indicating a common origin for both bands. As can be seen in figure 4 , in the case of $1-\mathrm{ANpH}^{+}$, the $22710 \mathrm{~cm}^{-1}$ band system $\mathrm{A} 1$ does not come from the same tautomer as the $31840 \mathrm{~cm}^{-1}$ band system D1. Likewise, it was observed that, for 2-ANpH , the $24170 \mathrm{~cm}^{-1}$ band system A2 comes from a different tautomer than the $31454 \mathrm{~cm}^{-1} \mathrm{C} 2$ band system. For the 
band system D2, the hole burning experiments are ambiguous because this band system is superimposed on a background, so the hole burning that is observed might be due to the background.
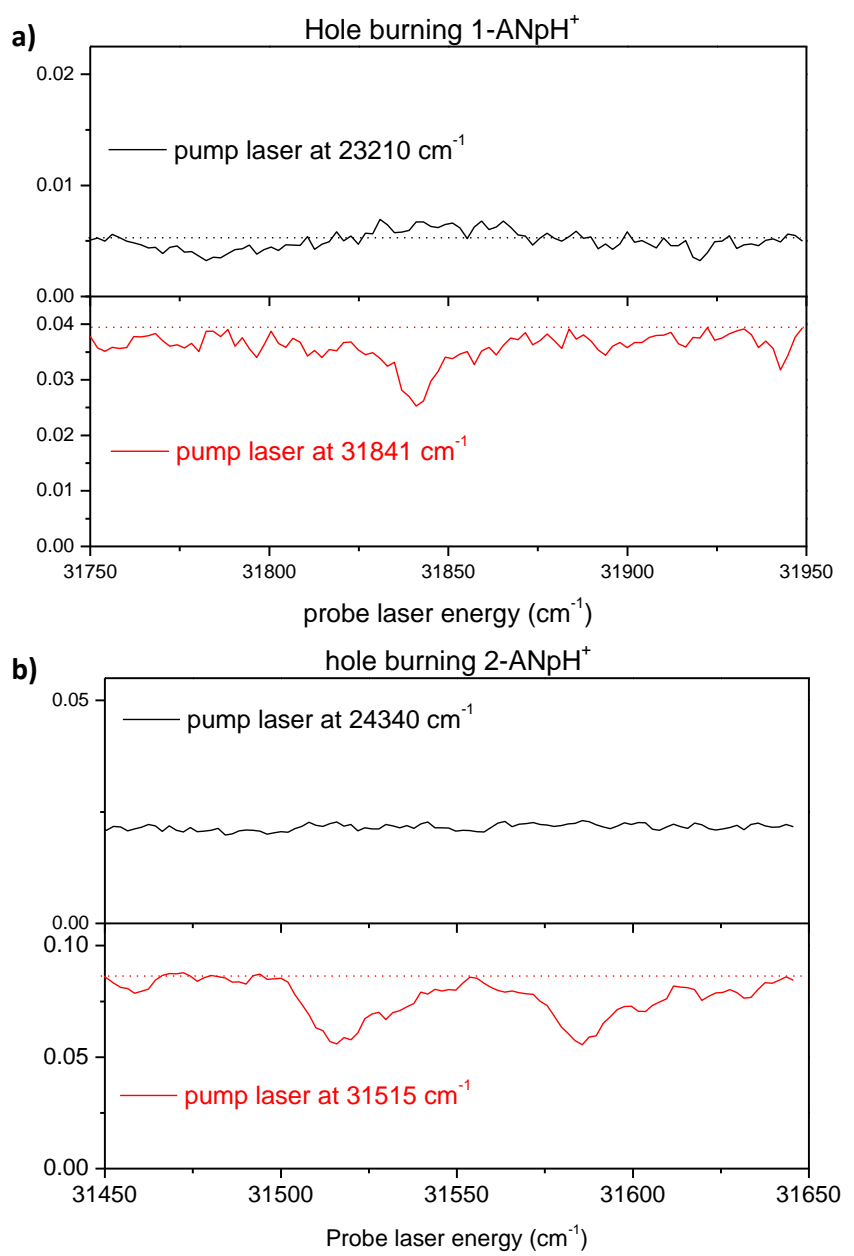

Figure 4: Hole burning experiment for 1-and 2-ANpH+:

a) lower panel: pump and probe (scanning) lasers are set to the first band of system D1 at $31841 \mathrm{~cm}^{-1} ; a$ depletion is observed in the fragment signal; upper panel: pump laser is set to the first visible system A1 at $23210 \mathrm{~cm}^{-1}$ and the probe laser scans the first band of system D1 around $31800 \mathrm{~cm}^{-1}$

b) lower panel: pump and probe laser are set to the first band of system C2 at $31515 \mathrm{~cm}^{-1}$; a depletion is observed in the fragment signal; upper panel: pump laser is set to the first visible system A2 at $24340 \mathrm{~cm}^{-}$ ${ }^{1}$ and the probe laser scans the first band of system C2 around $31500 \mathrm{~cm}^{-1}$

The absence of depletion indicates that the pumped and probed band systems do not originate from the same species. 
To complement the hole burning experiments, we measured additional spectra under different pressure conditions in the ion production region, aiming to change the relative concentration of tautomers in the $\operatorname{trap}^{51}$. As shown in the Supplementary Information (figure SI2 and SI-3), the increase of the pressure nearly entirely suppresses the signal in the visible region for both 1- and 2- $\mathrm{ANpH}^{+}$, while for the 2- $\mathrm{ANpH}^{+}$isomer the $\mathrm{UV}$ bands $\mathrm{D} 2$ and $\mathrm{E} 2$ are also suppressed. Clearly, increasing the pressure at the exit of the capillary and in the octopole favors one of the tautomers, i.e. the ammonium tautomer, as will be established below.

\section{Calculations}

\section{Protonation site}

Competition between protonation on the amino group and on carbon atoms of the aromatic cycles has already been observed for protonated monocyclic molecules such as protonated aniline ${ }^{7,15,21,52}$, hydroxy-benzoic acid ${ }^{11}$, aminobenzoic acid ${ }^{10,53}$, or aminophenol ${ }^{54}$ and in the polycyclic protonated 1-aminopyrene ${ }^{23}$. For $\mathrm{ANpH}^{+}$, the calculations shown in table 1 indicate that protonation on the amino group is not the most stable protonation site in these gas phase ions at low temperature. In table 1, DFT/B3LYP/cc-pVDZ calculations are given for all the tautomers, while $\operatorname{CCSD}(\mathrm{T})$ and MP4 calculations have only been performed for the most stable tautomers. The set of calculations obtained with different methods is given in the Supplementary Information (table SI-1).

Tautomers characterized by having a protonated carbon atom will be denoted as 1- or 2$\mathrm{ANpC}_{\mathrm{n}} \mathrm{H}_{2}{ }^{+}$, where $\mathrm{n}$ indicates the carbon number on which the proton is attached (see figure 1 for the atom numbering), and the tautomers protonated on the amino group will be referred to as 1 - or 2- $\mathrm{ANpNH}_{3}^{+}$. 
Table 1: Relative ground state energies calculated at the DFT/B3LYP level for the different 1- and 2-ANpH ${ }^{+}$ tautomers and complemented with $\operatorname{CSSD}(T)$ and MP4 calculations for the most stable tautomers. All calculations are performed with the cc-pVDZ basis set. The energies are relative to the ground state energy of the 1-ANpNH ${ }_{3}{ }^{+}$or $2-\mathrm{ANpNH}_{3}{ }^{+}$tautomers. All energies are in $\mathrm{eV}$. We report all $\mathrm{eV}$ values to the nearest $0.01 \mathrm{eV}$.

\begin{tabular}{|l|c|c|c|c|c|c|c|c|}
\hline & $1-\mathrm{ANpNH}_{3}{ }^{+}$ & $1-\mathrm{ANpC}_{2} \mathrm{H}_{2}^{+}$ & $1-\mathrm{ANpC}_{3} \mathrm{H}_{2}^{+}$ & $1-\mathrm{ANpC}_{4} \mathrm{H}_{2}^{+}$ & $1-\mathrm{ANpC}_{5} \mathrm{H}_{2}^{+}$ & $1-\mathrm{ANpC}_{6} \mathrm{H}_{2}^{+}$ & $1-\mathrm{ANpC}_{7} \mathrm{H}_{2}^{+}$ & $1-\mathrm{ANpC}_{8} \mathrm{H}_{2}^{+}$ \\
\hline DFT & 0 & -0.14 & +0.80 & -0.33 & +0.39 & +0.80 & +0.42 & +0.62 \\
\hline $\mathrm{CCSD}(\mathrm{T})$ & 0 & -0.032 & & -0.21 & & & & \\
\hline MP4 & 0 & +0.009 & & -0.17 & & & & \\
\hline
\end{tabular}

\begin{tabular}{|l|c|c|c|c|c|c|c|c|}
\hline & $2-\mathrm{ANpNH}_{3}{ }^{+}$ & $2-\mathrm{ANpC}_{1} \mathrm{H}_{2}^{+}$ & $2-\mathrm{ANpC}_{3} \mathrm{H}_{2}^{+}$ & $2-\mathrm{ANpC}_{4} \mathrm{H}_{2}^{+}$ & $2-\mathrm{ANpC}_{5} \mathrm{H}_{2}^{+}$ & $2-\mathrm{ANpC}_{6} \mathrm{H}_{2}^{+}$ & 2- $\mathrm{ANpC}_{7} \mathrm{H}_{2}^{+}$ & 2- $\mathrm{ANpC}_{8} \mathrm{H}_{2}^{+}$ \\
\hline DFT & 0 & -0.31 & +0.28 & +0.67 & +0.57 & +0.07 & +0.68 & +0.06 \\
\hline $\mathrm{CCSD}(\mathrm{T})$ & 0 & -0.14 & & & & +0.26 & & +0.29 \\
\hline $\mathrm{MP4}$ & 0 & -0.11 & & & & +0.32 & & +0.35 \\
\hline
\end{tabular}

As seen above, the 1-ANpC ${ }_{4} \mathrm{H}_{2}{ }^{+}$tautomer is always found to be more stable than the 1$\mathrm{ANpNH}_{3}{ }^{+}$tautomer, while the 1- $\mathrm{ANpC}_{2} \mathrm{H}_{2}{ }^{+}$tautomer seems to be almost isoenergetic with 1$\mathrm{ANpNH}_{3}{ }^{+}$. For $2-\mathrm{ANpH}^{+}$, the $2-\mathrm{ANpC}_{1} \mathrm{H}_{2}{ }^{+}$tautomer is more stable than the 2- $\mathrm{ANpNH}_{3}{ }^{+}$tautomer, while the 2- $\mathrm{ANpC}_{6} \mathrm{H}_{2}{ }^{+}$and $2-\mathrm{ANpC}_{8} \mathrm{H}_{2}{ }^{+}$tautomers are always less stable than the 2- $\mathrm{ANpNH}_{3}{ }^{+}$ tautomer.

In conclusion, the calculations indicate that protonation on the amino group is not the most stable protonation site in these isolated ions at low temperature.

\section{Calculated excited state transitions}

The assignment of these complicated spectra requires the use of high level ab-initio calculations. The vertical excitation energies and oscillator strengths of the first three excited states have been calculated for all the tautomers using the TD-DFT/ B3LYP (cc-pVDZ) method and for the most stable tautomers with the RI-CC2 (cc-pVDZ) method. The adiabatic transition energies of the two first excited states for the three most stable tautomers of 1-ANpH ${ }^{+}$and the four most stables ones of $2-\mathrm{ANpH}^{+}$have been calculated with the two methods. The complete set of calculations can be found in the SI, while only the calculations for the most stable tautomers are presented in table 2. 
Table 2: Calculated vertical excited state transition energies for the first three excited states of the most stable tautomers of 1- and 2-ANpH $\mathrm{H}^{+}$. Adiabatic transition energies have only been calculated for the $\mathrm{S}_{1}$ and $\mathrm{S}_{2}$ states of the most stable tautomers and the $\mathrm{S}_{3}$ state of $1-\mathrm{ANpC}_{4} \mathrm{H}_{2}{ }^{+}$. Oscillator strengths (o.s.) calculated with the DFT method are in italics.

\begin{tabular}{|c|c|c|c|c|c|c|c|c|c|c|c|}
\hline \multirow[t]{2}{*}{ tautomer } & \multicolumn{2}{|c|}{$\mathrm{S}_{1}$ vertical } & \multicolumn{2}{|c|}{$\mathrm{S}_{1}$ adiabatic } & \multicolumn{2}{|c|}{$S_{2}$ vertical } & \multicolumn{2}{|c|}{$\mathrm{S}_{2}$ adiabatic } & \multicolumn{2}{|c|}{$\mathrm{S}_{3}$ vertical } & \multirow{2}{*}{$\begin{array}{l}\mathrm{S}_{3} \\
\text { adia } \\
\mathrm{CC} 2\end{array}$} \\
\hline & $\begin{array}{l}\text { DFT } \\
\text { (o.s.) }\end{array}$ & $\mathrm{CC} 2$ & DFT & $\mathrm{CC} 2$ & $\begin{array}{l}\text { DFT } \\
\text { (o.s.) }\end{array}$ & $\mathrm{CC} 2$ & DFT & $\mathrm{CC} 2$ & $\begin{array}{l}\text { DFT } \\
\text { (o.s.) }\end{array}$ & $\mathrm{CC} 2$ & \\
\hline $1-\mathrm{ANpNH}_{3}{ }^{+}$ & $\begin{array}{l}4.18 \\
7.2 * 10^{-2}\end{array}$ & 4.40 & 3.93 & 4.25 & $\begin{array}{l}4.43 \\
6.2 * 10^{-3}\end{array}$ & $4.53^{*}$ & 4.32 & 4.39 & $\begin{array}{l}4.76 \\
6.5 * 10^{-4}\end{array}$ & 5.00 & \\
\hline 1-ANpC ${ }_{2} \mathrm{H}_{2}^{+}$ & $\begin{array}{l}3.03 \\
6.7 * 10^{-2}\end{array}$ & 3.24 & 2.62 & 2.84 & $\begin{array}{l}4.21 \\
9.4 * 10^{-2}\end{array}$ & 4.35 & 3.67 & 4.05 & $\begin{array}{l}4.76 \\
3.0 * 10^{-3}\end{array}$ & & \\
\hline 1- $\mathrm{ANpC}_{4} \mathrm{H}_{2}{ }^{+}$ & $\begin{array}{l}3.56 \\
2.1 * 10^{-2}\end{array}$ & 3.94 & 3.15 & 3.44 & $\begin{array}{l}4.06 \\
0.18\end{array}$ & 4.31 & 3.73 & 3.86 & $\begin{array}{l}5.11 \\
0.16\end{array}$ & 5.30 & 4.93 \\
\hline
\end{tabular}

\begin{tabular}{|c|c|c|c|c|c|c|c|c|c|c|}
\hline \multirow[t]{2}{*}{ tautomer } & \multicolumn{2}{|c|}{$\mathrm{S}_{1}$ vertical } & \multicolumn{2}{|c|}{$\mathrm{S}_{1}$ adiabatic } & \multicolumn{2}{|c|}{$\mathrm{S}_{2}$ vertical } & \multicolumn{2}{|c|}{$\mathrm{S}_{2}$ adiabatic } & \multicolumn{2}{|c|}{$\mathrm{S}_{3}$ vertical } \\
\hline & $\begin{array}{l}\text { DFT } \\
\text { (o.s.) }\end{array}$ & $\mathrm{CC} 2$ & DFT & $\mathrm{CC} 2$ & $\begin{array}{l}\text { DFT } \\
\text { (o.s.) }\end{array}$ & $\mathrm{CC} 2$ & DFT & CC2 & $\begin{array}{l}\text { DFT } \\
\text { (o.s.) }\end{array}$ & $\mathrm{CC} 2$ \\
\hline 2-ANpNH ${ }_{3}^{+}$ & $\begin{array}{l}4.12 \\
4 * 10^{-2} \\
\end{array}$ & 4.35 & 3.75 & 4.12 & $\begin{array}{l}4.36 \\
6 * 10^{-3} \\
\end{array}$ & 4.59 & 4.18 & 4.32 & $\begin{array}{l}4.56 \\
1 * 10^{-5} \\
\end{array}$ & 5.84 \\
\hline 2-ANpC ${ }_{1} \mathrm{H}_{2}{ }^{+}$ & $\begin{array}{l}3.22 \\
8 * 10^{-3} \\
\end{array}$ & 3.43 & 2.89 & 2.99 & $\begin{array}{l}3.46 \\
0.3 \\
\end{array}$ & 3.63 & 3.33 & 3.36 & $\begin{array}{l}5.28 \\
7 * 10^{-2} \\
\end{array}$ & 5.43 \\
\hline $2-\mathrm{ANpC}_{6} \mathrm{H}_{2}{ }^{+}$ & $\begin{array}{l}.18 \\
0.1\end{array}$ & 3.34 & 2.89 & 2.94 & $\begin{array}{l}4.05 \\
0.2 \\
\end{array}$ & 4.15 & 3.89 & 3.87 & $\begin{array}{l}4.87 \\
6 * 10^{-2} \\
\end{array}$ & 5.24 \\
\hline $2-\mathrm{ANpC}_{8} \mathrm{H}_{2}^{+}$ & $\begin{array}{l}3.19 \\
0.3\end{array}$ & 3.10 & 2.86 & 2.67 & $\begin{array}{l}3.60 \\
6 * 10^{-2}\end{array}$ & 3.85 & 3.21 & 3.20 & $\begin{array}{l}4.79 \\
9 * 10^{-3}\end{array}$ & 5.0 \\
\hline
\end{tabular}

* in $\mathrm{CC} 2$, the calculation of the $\mathrm{S}_{2}$ state for $1-\mathrm{ANpNH}_{3}{ }^{+}$has not converged since this state becomes isoenergetic with the $\mathrm{S}_{1}$ state and then the optimization process crashes: this state crossing may explain the broad band above $4.2 \mathrm{eV}$ on the $\mathrm{NH}_{3}$ loss channel.

The values obtained with the two methods give comparable results. For most of the tautomers, excited state optimizations conserve the planarity of the naphthalene skeleton. As already observed in many aromatic systems, the difference between vertical and adiabatic energies is on the order of $0.3 / 0.4 \mathrm{eV}$, which is usual for aromatic molecules ${ }^{16}$. These calculations are not corrected for the difference in zero point energy between $S_{0}$ and $S_{n}$ that has to be taken into account when comparing calculations with experimental results. The difference 
in zero point energy between $\mathrm{S}_{0}$ and $\mathrm{S}_{1}(\triangle \mathrm{ZPE})$ is $0.16 \mathrm{eV}$ for the 1- and 2-ANpNH${ }_{3}{ }^{+}$tautomers, and $0.12 \mathrm{eV}$ for $2-\mathrm{ANpC}_{1} \mathrm{H}_{2}{ }^{+}$and 1-ANpC ${ }_{4} \mathrm{H}_{2}{ }^{+}$.

\section{Discussion}

\section{Assignment of the band systems}

\section{Protonation on the amino group}

The assignment of the narrow band systems in the $4 \mathrm{eV}$ region (systems D1 and $\mathrm{C} 2$ ) to the spectra of the amino-protonated tautomers is straightforward as it can be considered that protonation on the amino group should lead to a spectrum similar to the naphthalene spectrum (band origin at $3.97 \mathrm{eV}$ ) or the neutral 1-aminonaphthalene at $3.72 \mathrm{eV}^{55}$. Furthermore, the calculated adiabatic transition energies, $4.09 \mathrm{eV}^{*}$ for 1- $\mathrm{ANpNH}_{3}{ }^{+}$and $3.94 \mathrm{eV}$ for $2-\mathrm{ANpNH}_{3}{ }^{+}$ (CC2/cc-pVDZ corrected for $\triangle \mathrm{ZPE}$ ), agree well with the observed band origins at 3.95 and 3.90 $\mathrm{eV}$, respectively. This assignment is also confirmed by the Franck Condon simulation performed for the first excited state of $1-\mathrm{ANpNH}_{3}{ }^{+}$(D1) shown in the SI (figure SI-4). The vibrational structure is quite similar to the vibrational structure of neutral aminonaphthalene, except that the $285 \mathrm{~cm}^{-1}$ mode is assigned to the $\mathrm{NH}_{2}$ out of plane inversion, which is missing in the protonated molecule because the inversion does not exist for the ammonium group. The assignment of the vibrational transitions is given in table $\mathrm{SI}-2$. For $2-\mathrm{ANpNH}_{3}{ }^{+}$, the Franck Condon simulation was not as conclusive as for the other isomer due to the out of plane deformation (see figure SI-5) in the excited state which seems to be overestimated with the CC2 method.

At higher energy, the broad band leading to a specific $\mathrm{H}$ loss (bands F1 and F2 in figure 1) can be assigned to the excitation of the Rydberg $\pi \sigma^{*}$ states, which are known to lead to the direct excited state $\mathrm{NH}$ dissociation ${ }^{24,56,57}$.

\section{Protonation on an aromatic carbon atom}

As for other protonated polycyclic aromatic molecules, the band systems in the visible and near UV region are characteristic of protonation on a carbon atom of the skeleton, as in the case of protonated naphthalene where the origin of the first transition is located at $2.46 \mathrm{eV}^{31,58}$. Hole burning experiments confirmed that the band systems in the visible and near UV do not come from the same tautomer as the $32000 \mathrm{~cm}^{-1}(4.0 \mathrm{eV})$ band systems (D1 and C2), which were 
assigned to the tautomers protonated on the amino group. Among all the possible C-protonated tautomers we selected those that have the lowest ground state energy: protonation on $\mathrm{C}_{2}$ and $\mathrm{C}_{4}$ for $1-\mathrm{ANpH}^{+}$and protonation on $\mathrm{C}_{1}$ for $2-\mathrm{ANpH}^{+}$. The band systems observed can be assigned by comparing the experimental results with calculations (table 3 and 4). For 1-ANpH ${ }^{+}$, the band systems $A 1$ and $B 1$ can be assigned, respectively, to the $S_{1} \leftarrow S_{0}$ transitions of the 1-ANpC $\mathrm{H}_{2}^{+}$ and 1-ANpC $\mathrm{H}_{2}{ }^{+}$tautomers. The $\mathrm{C} 1$ band system may originate from the $\mathrm{S}_{2} \leftarrow \mathrm{S}_{0}$ transition of either 1-ANpC ${ }_{2} \mathrm{H}_{2}{ }^{+}$or $1-\mathrm{ANpC}_{4} \mathrm{H}_{2}{ }^{+}$, which both have high oscillator strengths. For 2- $\mathrm{ANpH}^{+}$, the A2 band system is assigned to the $\mathrm{S}_{1} \leftarrow \mathrm{S}_{0}$ transition of the 2-ANpC${ }_{1} \mathrm{H}_{2}{ }^{+}$tautomer, which is the most stable tautomer. The B2 band may be assigned to the $S_{2} \leftarrow S_{0}$ transition of the same 2$\mathrm{ANpC}_{1} \mathrm{H}_{2}{ }^{+}$tautomer, which has a high oscillator strength. All the assignments are listed in table 3.

As for protonated naphthalene, the first electronic transitions of C-protonated tautomers of $\mathrm{ANpH}^{+}$appear in the visible spectral region due to the presence of low energy Charge Transfer states. For all the 1-ANpH tautomers, the $\mathrm{S}_{1}$ and $\mathrm{S}_{2}$ states correspond to HOMO $\rightarrow$ LUMO and HOMO-1 $\rightarrow$ LUMO transitions, as illustrated in figures SI-6 and SI-7. For the 1-ANpC ${ }_{4} \mathrm{H}_{2}{ }^{+}$tautomer and the 2-ANpC $\mathrm{H}_{2}{ }^{+}$, these transitions involve an electron transfer from the non-protonated ring toward an orbital which is more localized on the protonated ring (upper panel in figure SI-6). The strong CT character of these transitions leads to strongly red shifted spectra with respect to the neutral molecule, just as in the case of protonated naphthalene. The scenario changes when protonation occurs on the amino group, where the absorption involves orbitals (HOMO, HOMO1 and LUMO) that are well delocalized on the aromatic skeleton (figure SI-6 and SI-7 lower panels). As a result, the electronic transition appears weakly perturbed compared to the transition in the neutral molecule.

Table 3: Assignment of the observed band systems by comparison with excited state calculations.

\begin{tabular}{|c|c|c|c|}
\hline $\begin{array}{c}\text { 1-ANpH } \\
\text { Band systems in } \\
\text { figure 1a }\end{array}$ & $\begin{array}{c}\text { Tentative } \\
\text { assignment }\end{array}$ & $\begin{array}{c}\text { Calculated adiabatic } \\
\text { transitions corrected } \\
\text { for } \Delta \mathrm{ZPE} \\
\text { TD-DFT/CC2 }\end{array}$ & $\begin{array}{c}\text { Observed transitions } \\
\text { 1-ANpH }\end{array}$ \\
\hline $\mathrm{A} 1$ & 1- $\mathrm{ANpC}_{2} \mathrm{H}_{2}{ }^{+} \mathrm{S}_{1}$ & $2.46 / 2.68$ & 2.81 \\
\hline $\mathrm{B} 1$ & $1-\mathrm{ANpC}_{4} \mathrm{H}_{2}{ }^{+} \mathrm{S}_{1}$ & $2.99 / 3.28$ & 3.42 \\
\hline $\mathrm{C} 1$ & $1-\mathrm{ANpC}_{2} \mathrm{H}_{2}{ }^{+} \mathrm{S}_{2}$ or & $3.51 / 3.89$ & 3.90 \\
\hline
\end{tabular}




\begin{tabular}{|c|l|c|c|}
\hline & $1-\mathrm{ANpC}_{4} \mathrm{H}_{2}{ }^{+} \mathrm{S}_{2}$ & $3.57 / 3.70$ & \\
\hline $\mathrm{D} 1$ & $1-\mathrm{ANpNH}_{3}{ }^{+} \mathrm{S}_{1}$ & $3.77 / 4.09$ & 3.94 \\
\hline $\mathrm{E} 1$ & $1-\mathrm{ANpNH}_{3}{ }^{+} \mathrm{S}_{2}$ & $4.16 / 4.23$ & $\sim 4.00$ \\
\hline $\mathrm{F} 1$ & $1-\mathrm{ANpNH}_{3}{ }^{+} \pi \sigma^{*}$ & $-/ 5.59-\Delta \mathrm{ZPE}^{*}$ & $\sim 5.25$ \\
\hline
\end{tabular}

\begin{tabular}{|c|c|c|c|}
\hline $\begin{array}{c}\text { 2-ANpH } \\
\text { Band systems in } \\
\text { figure 1b }\end{array}$ & $\begin{array}{c}\text { Tentative } \\
\text { assignment }\end{array}$ & $\begin{array}{c}\text { Calculated adiabatic } \\
\text { transitions corrected } \\
\text { for } \Delta \mathrm{ZPE} \\
\text { TD-DFT/CC2 }\end{array}$ & $\begin{array}{c}\text { Observed transitions } \\
\text { 2-ANpH }\end{array}$ \\
\hline $\mathrm{A} 2$ & 2-ANpC $\mathrm{AH}_{2}{ }^{+} \mathrm{S}_{1}$ & $2.73 / 2.83$ & 3.00 \\
\hline $\mathrm{B} 2$ & $2-\mathrm{ANpC}_{1} \mathrm{H}_{2}{ }^{+} \mathrm{S}_{2}$ & $3.17 / 3.20$ & $\sim 3.20$ \\
\hline $\mathrm{C} 2$ & $2-\mathrm{ANpNH}_{3}{ }^{+} \mathrm{S}_{1}$ & $3.59 / 3.94$ & 3.90 \\
\hline $\mathrm{D} 2$ & & & 4.63 \\
\hline $\mathrm{E} 2$ & $2-\mathrm{ANpC}_{1} \mathrm{H}_{2}{ }^{+} \mathrm{S}_{3}$ & & $\sim 4.2$ \\
\hline $\mathrm{F} 2$ & $2-\mathrm{ANpNH}_{3}{ }^{+} \pi \sigma^{*}$ & & $\sim 5.25$ \\
\hline
\end{tabular}

For $1-\mathrm{ANpH}^{+}$, the assignment is unambiguous, since calculations and experiment are in good agreement. The assignment is more difficult for $2-\mathrm{ANpH}^{+}$: for example, the band at $4.63 \mathrm{eV}$ (D2) was thought to belong to the ammonium species but the pressure effect shows quite nicely that it does not (see section "In-source tautomerization" below and figure SI-3).

\section{Proton affinity}

\section{Proton affinity and calculation methods}

The proton affinity (PA) can be deduced from calculations. However, as can be seen in table 1 , the ground state energy difference between tautomers depends strongly on the calculation method (see also table SI-1). For protonated aniline, the best calculations ${ }^{21}$ at the CCSD(T)/augcc-pVTZ level including $\triangle Z P E$ give: $P A(N)=9.12 \mathrm{eV}$ for protonation on the amino group and $\mathrm{PA}(\mathrm{C} 4)=9.08 \mathrm{eV}$ for protonation on the $\mathrm{C} 4$ carbon atom. Such a costly calculation has been performed only for $1-\mathrm{ANpH}^{+}$, comparing protonation on the amino group and on the $\mathrm{C} 4$ carbon atom. The 1- $\mathrm{ANpC}_{4} \mathrm{H}_{2}{ }^{+}$tautomer was found more stable than the 1- $\mathrm{ANpNH}_{3}{ }^{+}$by $0.26 \mathrm{eV}$ when $\triangle Z P E$ is included. Since the values obtained with the CCSD(T)/cc-pVDZ and the DFT/B3lyp/ccpVDZ methods are in good agreement with this high level calculation, and bearing in mind that the $\operatorname{CCSD}(\mathrm{T})$ /aug-cc-pVTZ approach is too time consuming for large systems, we have chosen the cc-pVDZ basis set and the DFT method to investigate the evolution of the PA with the size of the $\mathrm{PAH}$ in a reasonable time. 


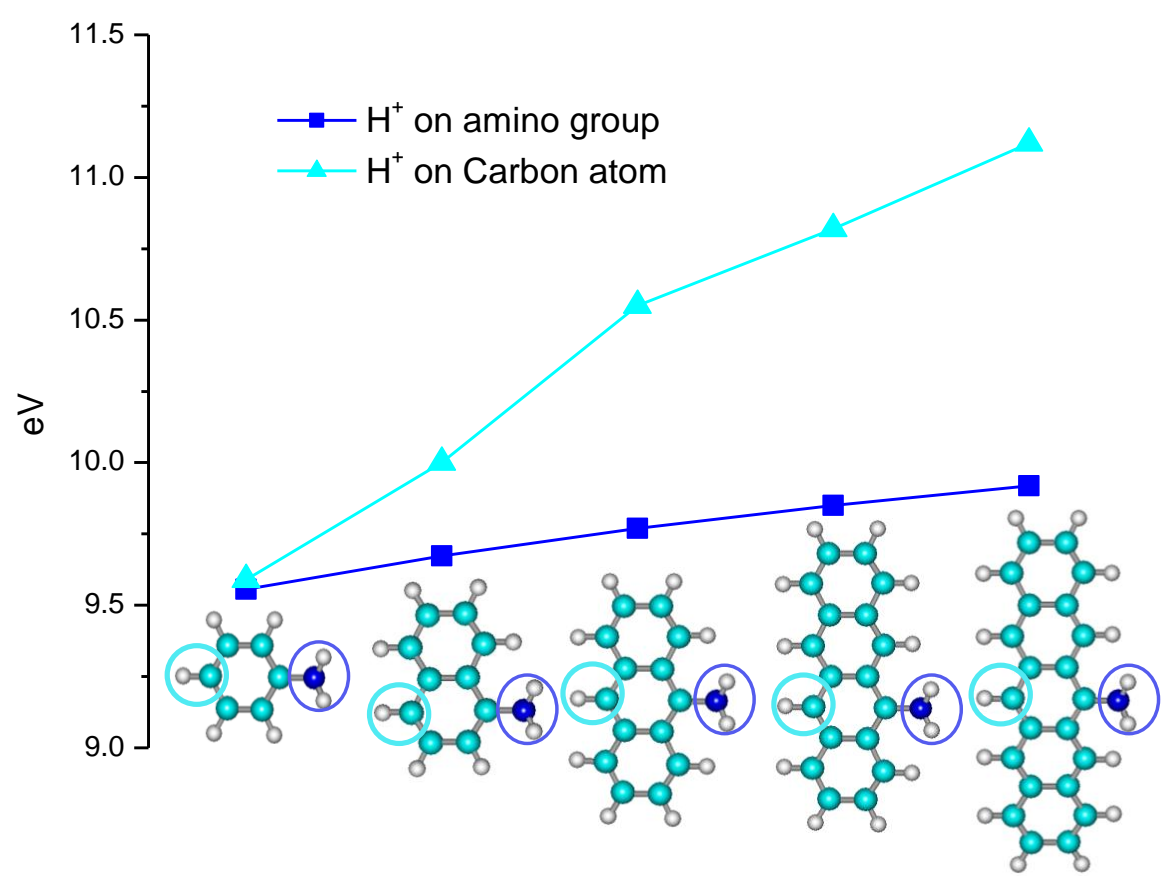

Figure 6: Evolution of the proton affinity with the size of the amino aromatic hydrocarbon. The change in ZPE between the protonated form and the neutral form has not been calculated for all the molecules. In the case of 1-ANpH $\mathrm{H}^{+}, \triangle P P E$ has been calculated to be $0.35 \mathrm{eV}$ for protonation on the amino group and slightly smaller for protonation on the carbon atom $(0.3 \mathrm{eV})$. The calculated proton affinity including $\triangle Z P E$ correction for this molecule, $9.3 \mathrm{eV}$ at the DFT/cc-pVDZ level, is in good agreement with the experimental value $(9.40 \mathrm{eV})$ reported in the literature ${ }^{50}$. The blue and cyan circles indicate the protonation sites.

\section{Proton affinity and PAH size}

Evolution of the proton affinity of the amino group with the PAH size.

The evolution of the PA of the amino group linked to an aromatic molecule is presented in figure 6 as a result of DFT calculations. The values show a slight increase of the proton affinity $(\triangle \mathrm{PA}<0.4 \mathrm{eV})$ as the substituted PAH size increases, from $9.56 \mathrm{eV}$ for aniline to $9.92 \mathrm{eV}$ for aminopentacene. Such a size effect on the PA can be explained in terms of the stabilization of the protonated ion. One would expect a larger PA in molecules that efficiently reduce the positive charge on the group where the proton is attached, e.g. by relocating electronic charge and contributing to the formation of a covalent bond. However, in amine-protonated PAHs a large portion of the charge remains on the ammonium group (e.g. Mulliken population analysis performed on 1-ANpNH${ }_{3}{ }^{+}$reveals that about $45 \%$ of the positive charge is retained in the $-\mathrm{NH}_{3}$ 
group) while the rest of it is withdrawn by the PAH moiety. To a first approximation, the amount of positive charge on the $-\mathrm{NH}_{3}$ substituent can be assumed invariant with the PAH's size because the inductive interaction with the aromatic system is short-range in nature. Therefore, the small size effect observed on the PA must rely on the energy gain caused by a better distribution of the excess positive charge in the aromatic skeleton when the number of fused rings increases. Further evidence supporting that the partial charge on the $-\mathrm{NH}_{3}$ substituent is not the dominant factor in explaining the PA's size behavior was given in a previous paper ${ }^{23}$ where we found that the electron attachment energy on the protonated ammonium group was $\mathrm{PAH}$ size independent, being $3.15 \mathrm{eV}$ for the series starting in $\mathrm{ANpH}^{+}$and ending in protonated aminopentacene.

\section{Evolution of proton affinity (PA) at the $\mathrm{C}_{\mathrm{n}}$ site with PAH size.}

The proton affinity of the $C_{n}$ site as a function of the PAH size has been calculated for the carbon atom in the para position to the amino group, namely $\mathrm{C}_{4}$ for naphthalene, $\mathrm{C}_{10}$ for anthracene, and so on (see figure 6). The selected structures are expected to be abundant tautomers because the addition of an electrophile, in particular a proton, to the $C_{n}$ site is strongly activated by the para-amino substituent. In contrast to what happens in ammonium ions, ring protonation is very efficient in delocalizing the excess positive charge away from the $\mathrm{C}_{\mathrm{n}}$ site. For example, a Mulliken charge calculation on $1-\mathrm{ANpC}_{4} \mathrm{H}_{2}{ }^{+}$shows that only $5 \%$ of the positive charge remains in the acceptor $\mathrm{C}_{4} \mathrm{H}_{2}$ group. The high PA values in figure 6 are explained in terms of the large stability of such arenium ions, in which a so-called covalent $\sigma$-complex is formed at the protonation site, i.e. $\mathrm{C}_{\mathrm{n}}$ acquires sp3 hybridization to attach two hydrogen atoms to the aromatic skeleton. Almost the entire positive charge is delocalized in the aromatic system ( $\sim 75 \%$ concentrates in the ring that hosts the proton, and $\sim 20 \%$ extends to the adjacent aromatic ring in the case of $\left.1-\mathrm{ANpC}_{4} \mathrm{H}_{2}{ }^{+}\right)$. In Scheme 1, we show the most relevant mesomeric structures in the case of $1-\mathrm{ANpC}_{4} \mathrm{H}_{2}{ }^{+}$that account for the efficient charge delocalization 
charge in protonated ring<smiles>NC1=C[CH+]Cc2ccccc21</smiles>

$15 \%$<smiles>N[C+]1C=CCCc2ccccc21</smiles>

$30 \%$<smiles>NC1=C2C=CC=C[C+]2CC1</smiles>

$10 \%$ charge in adjacent ring<smiles>[2H]C1C=CC(N)=C2C=C[CH+]C=C21</smiles>

$10 \%$

Scheme 1: Delocalization of the positive charge in the aromatic system of 1-ANpC $\mathrm{H}_{2}^{+}$via the mesomeric effect. The numbers indicate the percent weight of each mesomeric structure, according to a simple Mulliken analysis

As in the case of $-\mathrm{NH}_{2}$ protonation, the size effect observed on the PA can be rationalized in terms of the stabilization acquired by a better distribution of the excess positive charge in more extended PAHs. However, in the case of ring protonation the effect is larger because almost all the positive charge is delocalized in the aromatic system, in contrast to what happens in the amino protonated ions, where a fraction of the charge remains in the ammonium group.

The mesomeric effect can be evaluated by comparing the PA of the unsubstituted PAH with the PA of the amino-PAH, which results in a difference of more than one eV (1.4 eV) for aniline, decreasing as the PAH size increases, being $0.75 \mathrm{eV}$ for pentacene (see figure SI-8). For aminopentacene, the proton affinity reaches $11 \mathrm{eV}$, even larger than the PA of 1,8Bis(dimethylamino)naphthalene (called a "proton sponge" with a PA of $10.6 \mathrm{eV}$ ) ${ }^{50}$, which makes it a "superbase".

From these calculations it is clear that ring protonation is much more stable than amino protonation for large amino PAHs in the gas phase, which is not necessarily true in liquid, where the solvation energy has to be introduced as an important contribution.

\section{In-Source tautomerization}

Due to the large number of collisions at the exit of the capillary and in the first octopole trap, thermal equilibrium at room temperature is expected to be reached. Since the molecules stay, on average, $10 \mathrm{~s}$ in the octopole, they undergo around $10^{5}$ collisions before they are sent 
to the cold Paul trap through two low pressure chambers. If we now consider that the difference between the 2- $\mathrm{ANpNH}_{3}{ }^{+}$and the $2-\mathrm{ANpC}_{1} \mathrm{H}_{2}{ }^{+}$ground state energies (for ions in the gas phase) is $0.19 \mathrm{eV}(\mathrm{CCSD}(\mathrm{T})$ value corrected for $\triangle \mathrm{ZPE})$, it follows that, at room temperature, the 2- $\mathrm{ANpNH}_{3}{ }^{+}$population should be $\sim 5 * 10^{-4}$ times the population of the 2-ANpC $\mathrm{H}_{2}{ }^{+}$tautomer. In the case of $1-\mathrm{ANpH}^{+}$the values are slightly different, but again the $1-\mathrm{ANpNH}_{3}^{+}$population should be very small. However, an interesting observation is that the 1 - and $2-\mathrm{ANpNH}_{3}{ }^{+}$ contributions to the recorded UV spectra are the most intense ones. Why does the tautomer population in the trap not correspond to the energetic prediction? To answer this question we must pay attention to the effect of the solvent environment on the distribution of tautomers, and how the UV spectrum in the bulk will consequently exhibit remarkable differences with respect to that in vacuum. It has been shown, using the COSMO model with DFT/B3lyp/cc-pVDZ applied to protonated aminophenol, ${ }^{54}$ that protonation on the amino group is energetically favored in a polar medium such as water/methanol $(0.5 \mathrm{eV}$ compared to protonation on a carbon atom). A similar result was obtained (see table SI-3 at the DFT level) for 2-ANpH ${ }^{+}$, where the 2- $\mathrm{ANpC}_{1} \mathrm{H}_{2}{ }^{+}$tautomer, which is more stable than the $2-\mathrm{ANpNH}_{3}{ }^{+}$by $0.31 \mathrm{eV}$ in the gas phase, becomes less stable in the liquid phase by $0.24 \mathrm{eV}$. It is worth speculating on whether the ESI source might conserve part of the liquid phase tautomer distribution, which would favor the 2$\mathrm{ANpNH}_{3}{ }^{+}$population at the exit of the electrospray source, until the very last solvent molecules are vaporized. Under this assumption, the source-pressure effect observed in our experiment indicates that an increase of the backing pressure at the exit of the heated capillary above a few mbars favors the liquid phase tautomer, i.e. protonated on the amino group. Such conditions correspond to a diffusion regime in which elastic collisions between the molecules of interest and buffer gas (air) occur, without activation. This effect has already been observed when investigating in-source dissociation processes ${ }^{51,59}$. Here it is assumed that most of the activation of the ions occurs in the high pressure region of the ESI, with very weak increase of the internal energy in the octopole where the pressure is reduced by three orders of magnitude. In our case, the mean free path of the molecules $\left(\mathrm{N}_{2}\right.$ for air) at the exit of the capillary in front of the skimmer is estimated to be $1 \mathrm{~mm}(1 \mathrm{mBar} / 500 \mathrm{~K})$, and decreases by a factor of 10 when the pressure reaches $10 \mathrm{mBar}$. The distance between the exit of the capillary and the skimmer is on 
the order of $1 \mathrm{~mm}$ so, at high pressure, a diffusion regime will be reached, whereas at lower pressure, an intermediate regime (with both diffusional and collisional contributions, is expected to occur, under which ion activation cannot be neglected. It is, however, difficult to go beyond this qualitative explanation because of the concomitance of droplet evaporation and ion activation processes. In the former case, inelastic collisions fully desolvate the ions maintaining a low internal energy (evaporative cooling), while in the latter case, the energy increases to overcome the tautomerization and fragmentation barriers. So it seems reasonable to consider that when the pressure in the source is high, the tautomer distribution found in the liquid will be preserved to a large extent.

Provided that ESI tends to conserve the liquid phase structure, one has to be careful in the assignment of the most stable forms of protonated species when using electrospray sources and photofragmentation spectroscopy. It seems that ion mobility may be a better method ${ }^{60,59}$ as long as one can reach thermal equilibrium and if the collisional cross sections between tautomers are different enough ${ }^{27,28,30,56}$.

\section{Protonated amino group and $\pi \sigma *$ excited state}

For 1-ANpH ${ }^{+}$, a structureless transition leading specifically to $\mathrm{H}$ loss is observed at high energy, starting at $5.25 \pm 0.2 \mathrm{eV}$, which can be assigned to a $\pi \sigma *$ transition in which one electron of the $\pi$ orbital on the aromatic moiety is transferred on a diffuse Rydberg $\sigma^{*}$ orbital on the amino group. This state is well characterized in other amino-substituted aromatic molecules and is responsible for a direct $\mathrm{H}$ loss on the excited potential surface ${ }^{23}$. The adiabatic transition energy (uncorrected for $\triangle \mathrm{ZPE}$ ) has been calculated at $5.59 \mathrm{eV}$, which is in good agreement with the empirical formula ${ }^{23}$ where the $\pi \sigma *$ transition energy is derived from the difference between the ionization potential of the aromatic unsubstituted molecule and the electronic affinity of the ammonium group linked to an aromatic structure ( $8.14 \mathrm{eV}-3.15 \mathrm{eV}$ ). For $2-\mathrm{ANpH}^{+}$, the $\pi \sigma^{*}$ state is also observed in the $5.3 \mathrm{eV}$ energy region, but the onset is not well defined due the presence of a strong transition from another electronic state (band system $\mathrm{E} 2$, tentatively assigned to the $\mathrm{S}_{3}-\mathrm{S}_{0}$ transition of the $2-\mathrm{ANpC}_{1} \mathrm{H}_{2}{ }^{+}$tautomer). 


\section{Conclusions}

In this paper we have characterized the electronic properties of several tautomers of protonated 1- and 2- $\mathrm{ANpH}^{+}$by a combination of experiments and calculations. For both molecular ions, the first excited states of the amino-protonated and the aromatic skeletonprotonated tautomers were observed under our experimental conditions. Moreover, ab-initio calculations were found to be in good agreement with the experiment for such transitions, while the comparison was not as good for the higher excited states. By changing the pressure in the source, we were able to alter the tautomer distribution in the trap, which helped us in the assignment of some of the electronic bands corresponding to particular tautomers. This experimental procedure demonstrated that the tautomer distribution is very sensitive to the experimental conditions in the source, and that the observed population ratio in the trap does not necessarily reflect that found either in the liquid phase or in the gas phase at room temperature.

An interesting result derived from the calculations highlighted the fact that protonation in larger amino PAHs largely occurs on specific carbon atoms of the aromatic skeleton, rather than on the amino group. Large amino PAHs exhibit very large proton affinity values, and qualify as good candidates for being "proton sponges". It will be interesting to investigate how such carbocations behave in the conditions imposed by an ESI source, and if the relative proportions of $\mathrm{N}$ - and C-protonated ions could still be changed when the energy difference between the tautomers is larger.

\section{Acknowledgements}

We acknowledge the use of the computing facility cluster GMPCS of the LUMAT federation (LUMAT FR 2764). This works was supported by the ANR Research Grant (ANR2010BLANC040501_ESPEM) and have been conducted within the international CNRS/CONICET laboratory LEMIR. 


\section{Supplementary Information}

Figure SI-1: Photofragmentation spectra showing the branching ratio between the $\mathrm{m} / \mathrm{z} 115,117$, 127,143 fragments in the first band system of $1-\mathrm{ANpH}^{+}$; Figure $\mathrm{SI}-2$ : pressure effect on 2- $\mathrm{ANpH}^{+}$ photofragmentation in the spectral region of the D2 band ; Figure SI-3: pressure effect on 1$\mathrm{ANpNH}_{3}{ }^{+}$photofragmentation on the $314 \mathrm{~nm}$ band ; Figure SI-4: Franck Condon simulation of the first excited state of the 1- $\mathrm{ANpNH}_{3}{ }^{+}$tautomer ; Figure SI-5: optimized structure of the 2$\mathrm{ANpNH}_{3}{ }^{+} \mathrm{S}_{1}$ state ; Figure SI-6: orbitals involved in the two first electronic transitions in the 1$\mathrm{ANpC}_{4} \mathrm{H}_{2}{ }^{+}$and 1-ANpNH${ }_{3}+$ tautomers; Figure SI-7: orbitals involved in the two first electronic transitions in the 2- $\mathrm{ANpC}_{1} \mathrm{H}_{2}{ }^{+}$and $2-\mathrm{ANpNH}_{3}{ }^{+}$tautomers; Figure SI-8: Evolution of proton affinities (PA) with molecular size.

Table SI-1: Relative ground state energies calculated at different levels of theory for the 1- and 2-ANpH ${ }^{+}$tautomers; Table SI-2: Calculated frequencies of the first excited state of 1-ANpNH ${ }_{3}^{+}$ and tentative assignment of the bands observed; Table SI-3: Comparison of the calculated tautomer stability for ions isolated in the gas phase or ions in solution.

Energetics of the dissociation channels.

\section{References}

(1) Stearns, J. A.; Mercier, S.; Seaiby, C.; Guidi, M.; Boyarkin, O. V; Rizzo, T. R. Conformation-Specific Spectroscopy and Photodissociation of Cold, Protonated Tyrosine and Phenylalanine. J. Am. Chem. Soc. 2007, 129 (38), 11814-11820.

(2) Papadopoulos, G.; Svendsen, A.; Boyarkin, O. V.; Rizzo, T. R. Conformational Distribution of Bradykinin [bk+2 H]2+ Revealed by Cold Ion Spectroscopy Coupled with FAIMS. J. Am. Soc. Mass Spectrom. 2012, 23 (7), 1173-1181.

(3) Nagornova, N. S.; Rizzo, T. R.; Boyarkin, O. V. Highly Resolved Spectra of Gas-Phase Gramicidin S: A Benchmark for Peptide Structure Calculations. J. Am. Chem. Soc. 2010, 132, 4040-4041.

(4) Berdakin, M.; Steinmetz, V.; Maitre, P.; Pino, G. A. On the Ag+-cytosine Interaction: The Effect of Microhydration Probed by IR Optical Spectroscopy and Density Functional Theory. Phys. Chem. Chem. Phys. 2015, 17 (39), 25915-25924.

(5) Lorenz, U. J.; Rizzo, T. R. Multiple Isomers and Protonation Sites of the Phenylalanine/serine Dimer. J. Am. Chem. Soc. 2012, 134 (27), 11053-11055.

(6) Alata, I.; Bert, J.; Broquier, M.; Dedonder, C.; Feraud, G.; Grégoire, G.; Soorkia, S.; Jouvet, C.; Marceca, E.; Jouvet, C. Electronic Spectra of the Protonated Indole Chromophore in the Gas Phase. J. Phys. Chem. A 2013, 117 (21), 4420-4427.

(7) Lalli, P. M.; Iglesias, B. A.; Toma, H. E.; de Sa, G. F.; Daroda, R. J.; Silva Filho, J. C.; Szulejko, J. E.; Arakib, K.; Eberlin, M. N. Protomers: Formation, Separation and Characterization via Travelling Wave Ion Mobility Mass Spectrometry Authors. J. Mass. Spectrom. 2012, 47, 712-719.

(8) Coughlan, N. J. A.; Catani, K. J.; Adamson, B. D.; Wille, U.; Bieske, E. J. Photoisomerization Action 
Spectrum of Retinal Protonated Schiff Base in the Gas Phase. J. Chem. Phys. 2014, 140 (16).

(9) Cruz-Ortiz, A. F.; Rossa, M.; Berthias, F.; Berdakin, M.; Maitre, P.; Pino, G. A. Fingerprints of Both Watson-Crick and Hoogsteen Isomers of Isolated (Cytosine-Guanine) H+ Pair. J. Phys. Chem. Lett. 2017, 8, 5501-5506.

(10) Seo, J.; Warnke, S.; Gewinner, S.; Schöllkopf, W.; Bowers, M. T.; Pagel, K.; von Helden, G. The Impact of Environment and Resonance Effects on the Site of Protonation of Aminobenzoic Acid Derivatives. Phys. Chem. Chem. Phys. 2016, 18 (36), 25474-25482.

(11) Xia, H.; Attygalle, A. B. Effect of Electrospray lonization Source Conditions on the Tautomer Distribution of Deprotonated P-Hydroxybenzoic Acid in the Gas Phase. Anal. Chem. 2016, 88 (11), 6035-6043.

(12) Morsa, D.; Gabelica, V.; Rosu, F.; Oomens, J.; De Pauw, E. Dissociation Pathways of Benzylpyridinium "thermometer" ions Depend on the Activation Regime: An IRMPD Spectroscopy Study. J. Phys. Chem. Lett. 2014, 5 (21), 3787-3791.

(13) Solcà, N.; Dopfer, O. Protonation of Aromatic Molecules: Competition between Ring and Oxygen Protonation of Phenol (Ph) Revealed by IR Spectra of PhH+-Arn. Chem. Phys. Lett. 2001, 342, 191.

(14) Chiavarino, B.; Crestoni, M. E.; Fornarini, S.; Dopfer, O.; Lemaire, J.; Maitre, P. IR Spectroscopic Features of Gaseous C H O Ions : Benzylium versus Tropylium. J. Phys. Chem. A 2006, 110, 93529360.

(15) Pasker, F. M.; Solcà, N.; Dopfer, O. Spectroscopic Identification of Carbenium and Ammonium Isomers of Protonated Aniline (AnH+): IR Spectra of Weakly Bound AnH +-Ln Clusters ( $L=A r, N 2)$. J. Phys. Chem. A 2006, 110 (47), 12793-12804.

(16) Berdakin, M.; Féraud, G.; Dedonder-Lardeux, C.; Jouvet, C.; Pino, G. A. Excited States of Protonated DNA/RNA Bases. Phys. Chem. Chem. Phys. 2014, 16, 10643-10650.

(17) Kang, H.; Féraud, G.; Dedonder-lardeux, C.; Jouvet, C. New Method for Double-Resonance Spectroscopy in a Cold Quadrupole Ion Trap and Its Application to UV - UV Hole-Burning Spectroscopy of Protonated Adenine Dimer. J. Phys. Chem. Lett. 2014, 5, 2760.

(18) Féraud, G.; Dedonder, C.; Jouvet, C.; Inokuchi, Y.; Haino, T.; Sekiya, R.; Ebata, T. Development of Ultraviolet - Ultraviolet Hole-Burning Spectroscopy for Cold Gas-Phase lons. J. Phys. Chem. Lett. 2014, 5, 1236-1240.

(19) Ishiuchi, S.; Wako, H.; Kato, D.; Fujii, M. High-Cooling-Efficiency Cryogenic Quadrupole Ion Trap and UV-UV Hole Burning Spectroscopy of Protonated Tyrosine. J. Mol. Spectrosc. 2017, 332, 4551.

(20) Lorenz, U. J.; Solcà, N.; Lemaire, J.; Maître, P.; Dopfer, O.; Maitre, P. Infrared Spectra of Isolated Protonated Polycyclic Aromatic Hydrocarbons: Protonated Naphthalene. Angew. Chem. Int. Ed. Engl. 2007, 46 (35), 6714-6716.

(21) Flammang, R.; Dechamps, N.; Pascal, L.; Haverbeke, Y.; Gerbaux, P.; Nam, P.-C.; Nguyen, M. Ring Versus Nitrogen Protonation of Anilines. Lett. Org. Chem. 2004, 1 (1), 23-30.

Lalli, P. M.; Iglesias, B. A.; Toma, H. E.; De Sa, G. F.; Daroda, R. J.; Silva Filho, J. C.; Szulejko, J. E.; 
Araki, K.; Eberlin, M. N. Protomers: Formation, Separation and Characterization via Travelling Wave Ion Mobility Mass Spectrometry. J. Mass Spectrom. 2012, 47 (6), 712-719.

(23) Noble, J. A.; Dedonder-Lardeux, C.; Mascetti, J.; Jouvet, C. Electronic Spectroscopy of Protonated 1-Aminopyrene in a Cold Ion Trap. Chem. - An Asian J. 2017, 125, 1523-1531.

(24) Sobolewski, A. L.; Domcke, W.; Dedonder-Lardeux, C.; Jouvet, C. Excited-State Hydrogen Detachment and Hydrogen Transfer Driven by Repulsive $1 \pi \sigma^{*}$ States: A New Paradigm for Nonradiative Decay in Aromatic Biomolecules. Phys. Chem. Chem. Phys. 2002, 4 (7), 1093-1100.

(25) Kang, H.; Dedonder-Lardeux, C.; Jouvet, C.; Grégoire, G.; Desfrançois, C.; Schermann, J.-P.; Barat, M.; Fayeton, J. A. Control of Bond-Cleaving Reactions of Free Protonated Tryptophan lon by Femtosecond Laser Pulses. J. Phys. Chem. A 2005, 109 (11), 2417-2420.

(26) Kang, H.; Dedonder-Lardeux, C.; Jouvet, C.; Martrenchard, S.; Grégoire, G.; Desfrançois, C.; Schermann, J.-P.; Barat, M.; Fayeton, J. A. Photo-Induced Dissociation of Protonated Tryptophan TrpH+: A Direct Dissociation Channel in the Excited States Controls the Hydrogen Atom Loss. Phys. Chem. Chem. Phys. 2004, 6 (10), 2628-2632.

(27) Grégoire, G.; Jouvet, C.; Dedonder, C.; Sobolewski, A. L. Ab Initio Study of the Excited-State Deactivation Pathways of Protonated Tryptophan and Tyrosine. J. Am. Chem. Soc. 2007, 129 (19), 6223-6231.

(28) Lepere, V.; Lucas, B.; Barat, M.; Fayeton, J. A.; Picard, Y. J.; Jouvet, C.; Çarçabal, P.; Nielsen, I. B.; Dedonder-Lardeux, C.; Grégoire, G.; et al. Comprehensive Characterization of the Photodissociation Pathways of Protonated Tryptophan. J. Chem. Phys. 2007, 127 (13), 134313.

(29) Grégoire, G.; Lucas, B.; Barat, M.; Fayeton, J. A.; Dedonder-Lardeux, C.; Jouvet, C. UV Photoinduced Dynamics in Protonated Aromatic Amino Acid. Eur. Phys. J. D 2009, 51 (1), 109116.

(30) Féraud, G.; Broquier, M.; Dedonder, C.; Jouvet, C.; Gregoire, G.; Soorkia, S. Excited-State Dynamics of Protonated Phenylalanine and Tyrosine: Photo-Induced Reactions Following Electronic Excitation. J. Phys. Chem. A 2015, 119, 5914-5924.

(31) Alata, I.; Omidyan, R.; Broquier, M.; Dedonder, C.; Dopfer, O.; Jouvet, C. Effect of Protonation on the Electronic Structure of Aromatic Molecules: naphthaleneH(+). Phys. Chem. Chem. Phys. 2010, $12,14456-14458$.

(32) Burke, N. L.; Redwine, J. G.; Dean, J. C.; Mcluckey, S. A.; Zwier, T. S. UV and IR Spectroscopy of Cold Protonated Leucine Enkephalin. Int. J. Mass Spectrom. 2015, 378, 196-205.

(33) Inokuchi, Y.; Haino, T.; Sekiya, R.; Morishima, F.; Dedonder, C.; Raldine, G.; Raud, F.; Jouvet, C.; Ebata, T. UV Photodissociation Spectroscopy of Cryogenically Cooled Gas Phase Host Guest Complex lons of Crown Ethers. Phys. Chem. Chem. Phys. 2015, 17 (17), 25925-25934.

(34) Choi, C. M.; Choi, D. H.; Kim, N. J.; Heo, J. Effective Temperature of Protonated Tyrosine lons in a Cold Quadrupole Ion Trap. Int. J. Mass Spectrom. 2012, 314, 18-21.

(35) Günther, A.; Nieto, P.; Müller, D.; Sheldrick, A.; Gerlich, D.; Dopfer, O. BerlinTrap: A New Cryogenic 22-Pole Ion Trap Spectrometer. J. Mol. Spectrosc. 2017, 332, 8-15. 
(36) Kamrath, M. Z.; Relph, R. a.; Guasco, T. L.; Leavitt, C. M.; Johnson, M. a. Vibrational Predissociation Spectroscopy of the H2-Tagged Mono- and Dicarboxylate Anions of Dodecanedioic Acid. Int. J. Mass Spectrom. 2010, 300 (2-3), 91-98.

(37) Wang, X.-B.; Wang, L.-S. Development of a Low-Temperature Photoelectron Spectroscopy Instrument Using an Electrospray lon Source and a Cryogenically Controlled Ion Trap. Rev. Scien. Inst. 2008, 79 (7), 73108.

(38) Wang, L.-S. Perspective: Electrospray Photoelectron Spectroscopy: From Multiply-Charged Anions to Ultracold Anions. J. Chem. Phys. 2015, 143 (4), 40901.

(39) Marsh, B. M.; Voss, J. M.; Garand, E. A Dual Cryogenic lon Trap Spectrometer for the Formation and Characterization of Solvated lonic Clusters. J. Chem. Phys. 2015, 143 (20), 204201.

(40) Andersen, J. U.; Cederquist, H.; Forster, J. S.; Huber, B. A.; Hvelplund, P.; Jensen, J.; Liu, B.; Manil, B.; Maunoury, L.; Nielsen, S. B.; et al. Photodissociation of Protonated Amino Acids and Peptides in an Ion Storage Ring. Determination of Arrhenius Parameters in the High-Temperature Limit. Phys. Chem. Chem. Phys. 2004, 6 (10), 2676-2681.

(41) Esteves-López, N.; Dedonder-Lardeux, C.; Jouvet, C. Excited State of Protonated Benzene and Toluene. J. Chem. Phys. 2015, 143 (7), 74303.

(42) TURBOMOLE V6-6 2011, a development of University of Karlsruhe and Forschungszentrum Karlsruhe GmbH, 1989-2007, TURBOMOLE GmbH, since 2007; available from http://www.turbomole.com.

(43) Hattig, C. Geometry Optimizations with the Coupled-Cluster Model CC2 Using the Resolution Identity Approximation. J. Chem. Phys. 2003, 118 (17), 7751-7761.

(44) Hättig, C. Optimization of Auxiliary Basis Sets for RI-MP2 and RI-CC2 Calculations: Core?valence and Quintuple-? Basis Sets for H to Ar and QZVPP Basis Sets for Li to Kr. Phys. Chem. Chem. Phys. 2005, 7 (1), 59.

(45) Hättig, C.; Weigend, F. CC2 Excitation Energy Calculations on Large Molecules Using the Resolution of the Identity Approximation. J. Chem. Phys. 2000, 113 (13), 5154.

(46) Woon, D. E. .; Dunning Jr., T. H. Gaussian Basis Sets for Use in Correlated Molecular Calculations. III. The Atoms Aluminum through Argon. J. Chem. Phys. 1993, 98, 1358.

PGOPHER, a Program for Simulating Rotational Structure, C. M. Western, University of Bristol, Http://pgopher.chm.bris.ac.uk. PGOPHER, a Program for Simulating Rotational Structure, C. M. Western, University of Bristol, http://pgopher.chm.bris.ac.uk.

(48) Broquier, M.; Soorkia, S.; Dedonder-Lardeux, C.; Jouvet, C.; Theulé, P.; Grégoire, G. Twisted Intramolecular Charge Transfer in Protonated Amino Pyridine. J. Phys. Chem. A 2016, 120 (21), 3797-3809.

(49) Wang, Z.; Cole, C. A.; Snow, T. P.; Bierbaum, V. M. Experimental and Computational Studies of the Formation Mechanism of Protonated Interstellar Diazines. Astrophys. J. 2015, 798:102, 1-8.

(50) Linstrom, P. J.; Mallard, W. G. NIST Chem. WebBook, NIST Standard Reference Database Number 69. National Institute Standards and Technology 2003. 
(51) Schmidt, A.; Bahr, U.; Karas, M. Influence of Pressure in the First Pumping Stage on Analyte Desolvation and Fragmentation in Nano-ESI MS. Anal. Chem. 2001, 73 (24), 6040-6046.

(52) Boschmans, J.; Jacobs, S.; Williams, J. P.; Palmer, M.; Richardson, K.; Giles, K.; Lapthorn, C.; Herrebout, W. A.; Lemière, F.; Sobott, F. Combining Density Functional Theory (DFT) and Collision Cross-Section (CCS) Calculations to Analyze the Gas-Phase Behaviour of Small Molecules and Their Protonation Site Isomers. Anlyst 2016, 141 (13), 4044-4054.

(53) Warnke, S.; Seo, J.; Boschmans, J.; Sobott, F.; Scrivens, J. H.; Bleiholder, C.; Bowers, M. T.; Gewinner, S.; Schöllkopf, W.; Pagel, K.; et al. Protomers of Benzocaine: Solvent and Permittivity Dependence. J. Am. Chem. Soc. 2015, 137 (12), 4236-4242.

(54) Féraud, G.; Esteves-López, N.; Dedonder-Lardeux, C.; Jouvet, C. UV Spectroscopy of Cold lons as a Probe of the Protonation Site. Phys. Chem. Chem. Phys. 2015, 17, 25755-25760.

(55) Lahmani, F.; Zehnacker-Rentien, A.; Coudert, L. H.; Zachariasse, K. A. Spectroscopic Studies of the S0-S1 Transition of Substituted 1-Aminonaphthalenes in a Supersonic Jet. J. Phys. Chem. A 2003, 107 (38), 7364-7372.

(56) Kang, H.; Jouvet, C.; Dedonder-Lardeux, C.; Martrenchard, S.; Grégoire, G.; Desfrançois, C.; Schermann, J.-P. P.; Barat, M.; Fayeton, J. A.; Grégoire, G.; et al. Ultrafast Deactivation Mechanisms of Protonated Aromatic Amino Acids Following UV Excitation. Phys. Chem. Chem. Phys. 2005, 7 (2), 394-398.

(57) Grégoire, G.; Jouvet, C.; Dedonder, C.; Sobolewski, A. L. On the Role of Dissociative $(\pi \sigma)^{*}$ States in the Photochemistry of Protonated Tryptamine and Tryptophan: An Ab Initio Study. Chem. Phys.

2006, $324(2-3), 398-404$.

(58) Alata, I.; Dedonder, C.; Broquier, M.; Marceca, E.; Jouvet, C. Role of the Charge-Transfer State in the Electronic Absorption of Protonated Hydrocarbon Molecules. J. Am. Chem. Soc. 2010, 132 (14), 17483-17489.

(59) Georgiou, D. C.; Haghighatbin, M. A.; Hogan, C. F.; Scholz, M. S.; Bull, J. N.; Bieske, E. J.; Wilson, D. J. D.; Dutton, J. L. A Strong Cis-Effect in an Imidazole-Imidazolium-Substituted Alkene. Angew. Chemie - Int. Ed. 2017, 56 (29), 8473-8480.

(60) Pierson, N. A.; Clemmer, D. E. An IMS-IMS Threshold Method for Semi-Quantitative Determination of Activation Barriers: Interconversion of Proline Cis-Trans Forms in Triply Protonated Bradykinin. Int. J. Mass Spectrom. 2014, 377, 646-654. 


\section{Supplementary information}

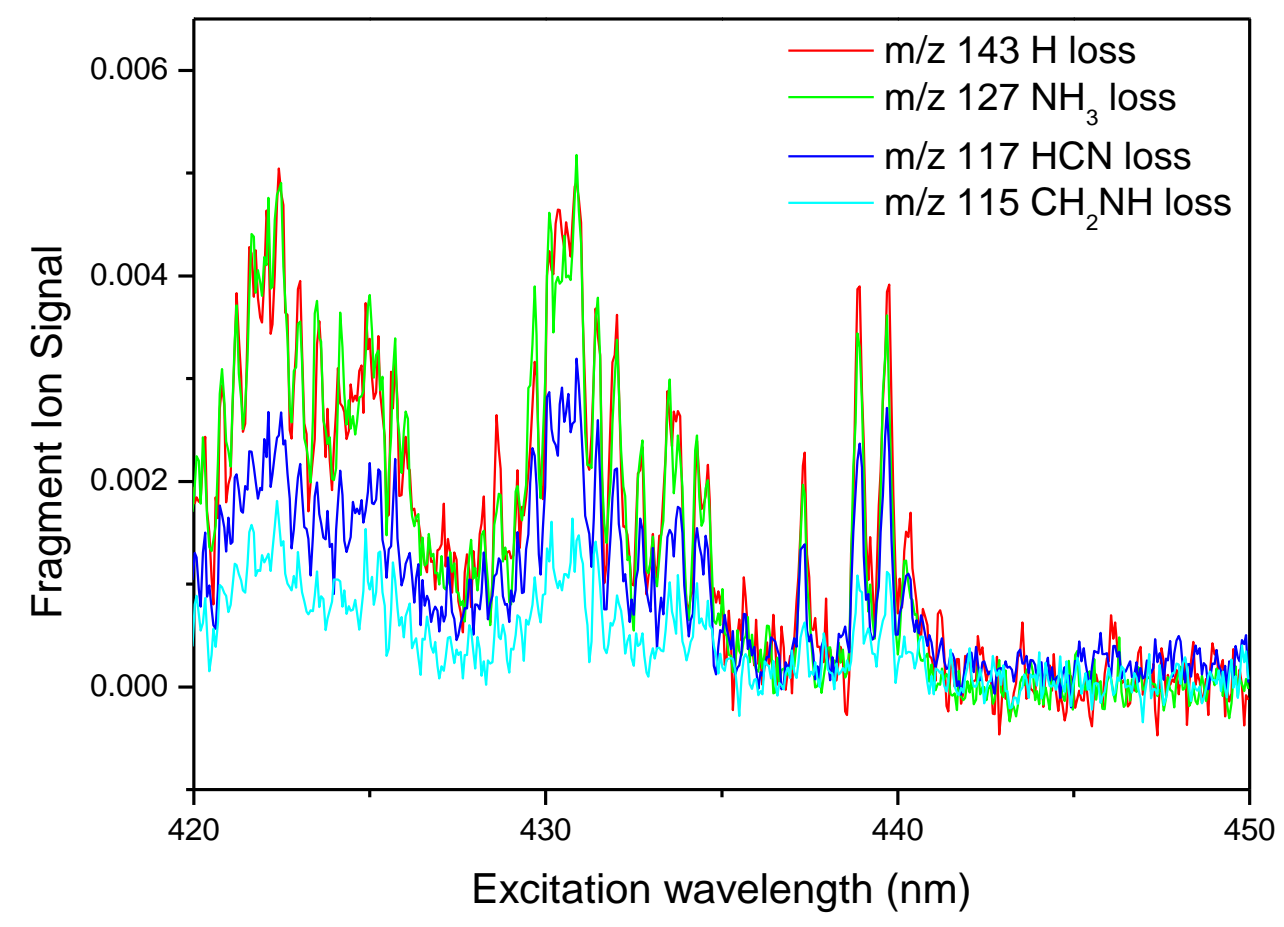

Figure SI-1: Photofragmentation spectra recorded on different fragments in the first band system of 1$A \mathrm{NpH}^{+}$around $440 \mathrm{~nm}$, showing that the branching ratio between the $\mathrm{m} / \mathrm{z} 115 / 117 / 127 / 143$ fragmentation channels is $1 / 2 / 3 / 3$. 


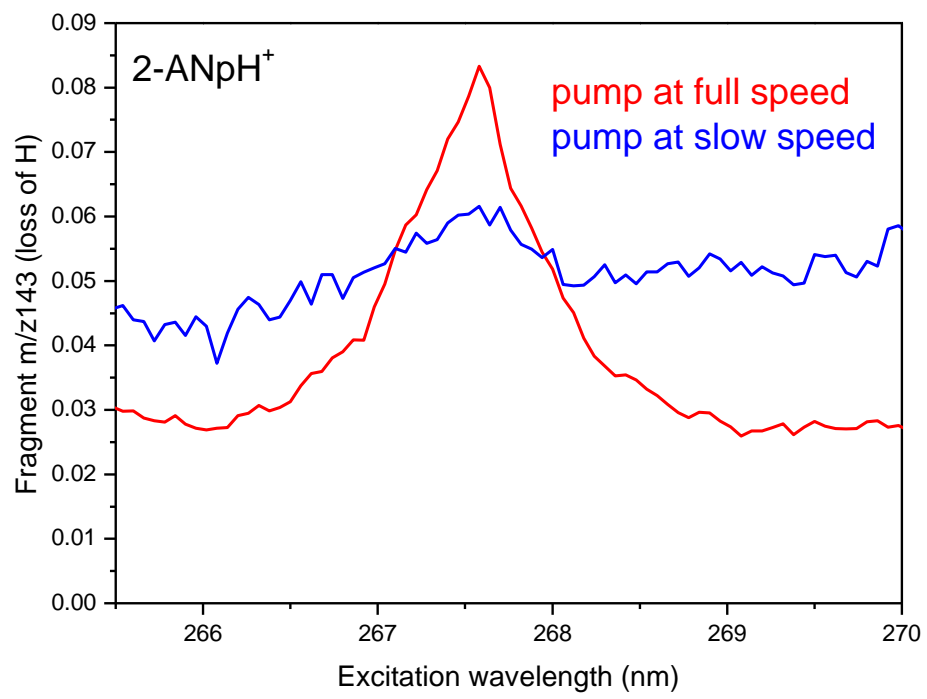

Figure SI-2: 2-ANpH photofragmentation spectrum in the UV spectral region of the D2 band: effect of decreasing the pumping speed (i.e. increasing the pressure) in the ion formation region. In red, low pressure conditions, both the background due to the 2-ANpNH ${ }_{3}^{+}$tautomer and the D2 band at $267 \mathrm{~nm}$ are observed; in blue, high pressure conditions, the $267 \mathrm{~nm}$ band disappears and the background increases, which means that the D2 band system does not correspond to an excited state of the $2-\mathrm{ANpNH}_{3}{ }^{+}$tautomer.

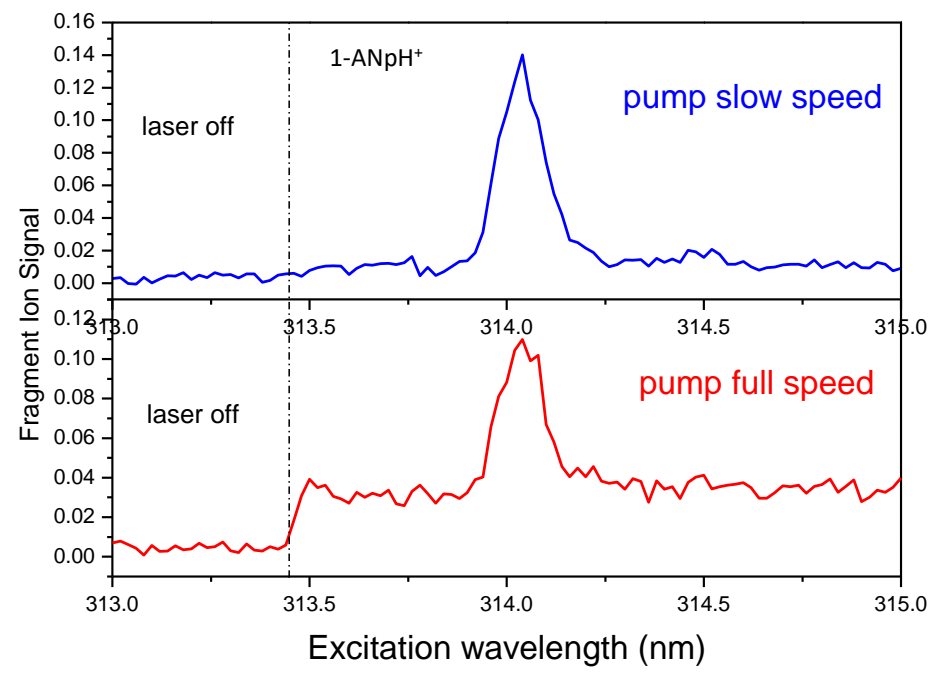

Figure SI-3: 1-ANpH photofragmentation spectra under different pressure conditions in the first octopole chamber: upper panel in blue, under high pressure conditions, only the band at $314 \mathrm{~nm}$ assigned to the species protonated on 
the amino group (1-ANpNH$\left.{ }_{3}^{+}\right)$is observed; lower panel in red, under lower pressure conditions, the background assigned to the 1-ANpC $\mathrm{H}_{2}^{+}$tautomers is also observed.

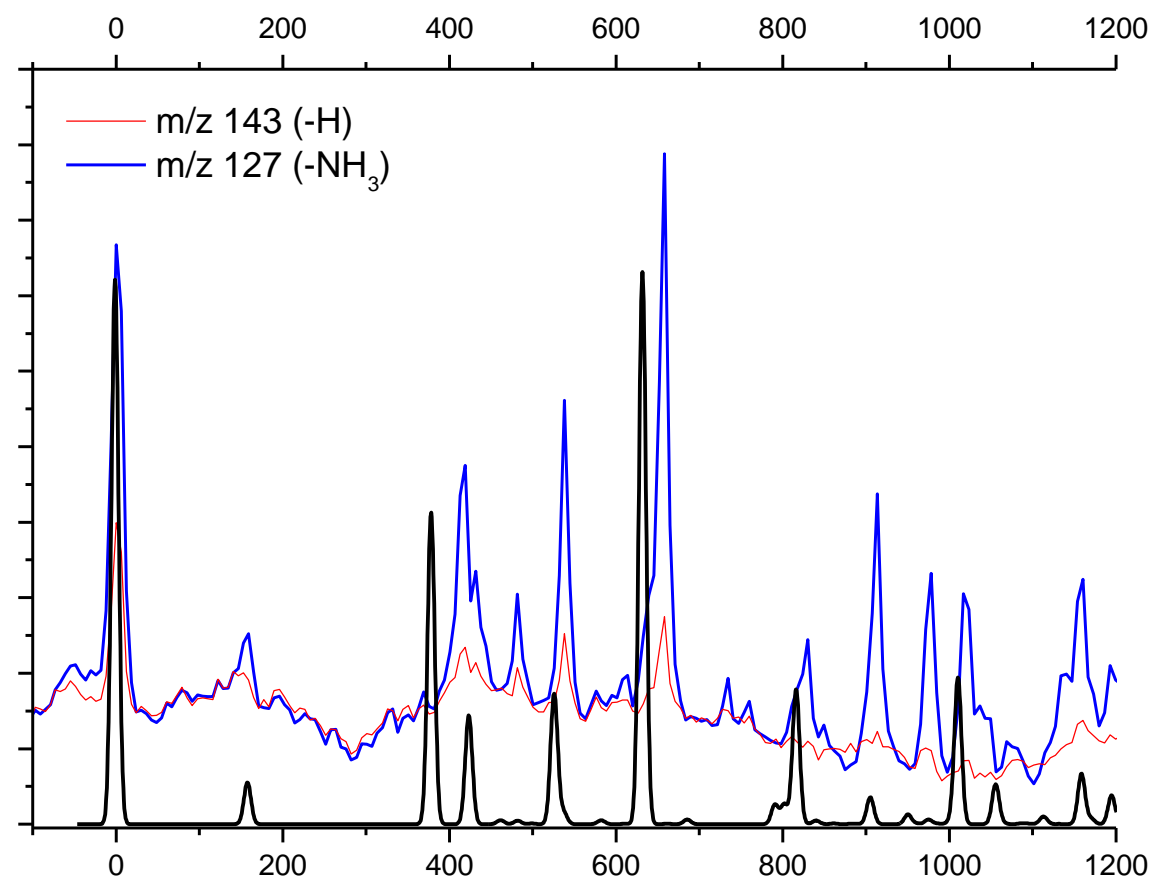

Figure SI-4: Franck Condon simulation of the first excited state of the 1-ANpNH ${ }_{3}{ }^{+}$tautomer (obtained using the Pgopher program) compared to the experimental photofragmentation spectrum. 


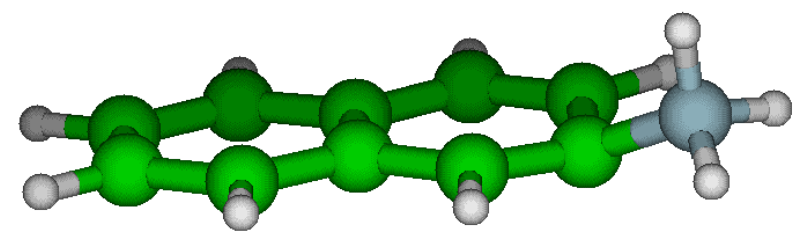

Figure SI-5: optimized structure of the 2-ANpNH${ }_{3}{ }^{+} \mathrm{S}_{1}$ state calculated at the CC2/aug-cC-pVDZ level. The ammonium group is slightly out of the naphthalene plane by $24^{\circ}$.

\section{Cartesian coordinates of the above structure}

$\begin{array}{rrrr}\text { ATOM } & & \text { CARTESIAN COORDINATES } \\ 1 & \mathrm{c} & -0.03237626647460 & 0.09295118508548 \\ 2 & \mathrm{c} & -0.10249855734972 & 0.19259376721050 \\ 3 & \mathrm{c} & 2.29804003945061 & -0.06849833538860 \\ 4 & \mathrm{c} & 4.68397747486221 & -0.13083661528096 \\ 5 & \mathrm{c} & 2.33852138400495 & -0.13966551106242 \\ 6 & \mathrm{~h} & 0.56905298765013 & -0.08399262607070 \\ 7 & \mathrm{c} & 7.02194143835557 & -0.33875175091409 \\ 8 & \mathrm{~h} & 8.77753027802044 & -0.54407179763194 \\ 9 & \mathrm{c} & 4.66231551952435 & -0.31126091068176 \\ 10 & \mathrm{~h} & 4.65025822049470 & -0.28120996077809 \\ 11 & \mathrm{c} & 6.98251238547425 & -0.65221729762236 \\ 12 & \mathrm{~h} & 9.33253814820944 & 0.19441807245318 \\ 13 & \mathrm{c} & 2.20332917266613 & 0.13059554005356 \\ 14 & \mathrm{c} & 4.56026959634376 & -0.03108564850672 \\ 15 & \mathrm{~h} & 6.32169058283750 & -0.08088552649927 \\ 16 & \mathrm{~h} & 2.24278301775756 & 0.20768095259240 \\ 17 & \mathrm{~h} & -1.90058026239914 & 0.31470656848563 \\ 18 & \mathrm{~h} & 9.21633557954636 & -0.17755894483688 \\ 19 & \mathrm{~h} & -1.80247979280076 & 0.13505675887722 \\ 20 & \mathrm{~h} & 10.88418153253196 & -0.76079644884641 \\ 21 & \mathrm{~h} & 9.69335385620823 & 2.12030992845785\end{array}$

0.01886026215097 2.70265055076771 $-1.35743673585278$ $-0.00584351228890$ $-4.05848632755360$ $-5.12850198931318$ $-1.31536065729741$ $-0.23019803727113$ $-5.35659497028840$ $-7.43099384434985$ $-4.02310621736102$ $-5.37729548294762$ 4.00712453048840 2.67148689996979 3.76283729991732 6.07407526899866 3.70897896369729 $-7.28343006161966$ $-1.05759368125755$ $-4.70450733749599$ $-5.14511351326717$ 
Figure SI-6: orbitals involved in the two first electronic transitions in the 1- $\mathrm{ANpC}_{4} \mathrm{H}_{2}{ }^{+}$and 1ANpNH ${ }_{3}{ }^{+}$tautomers.
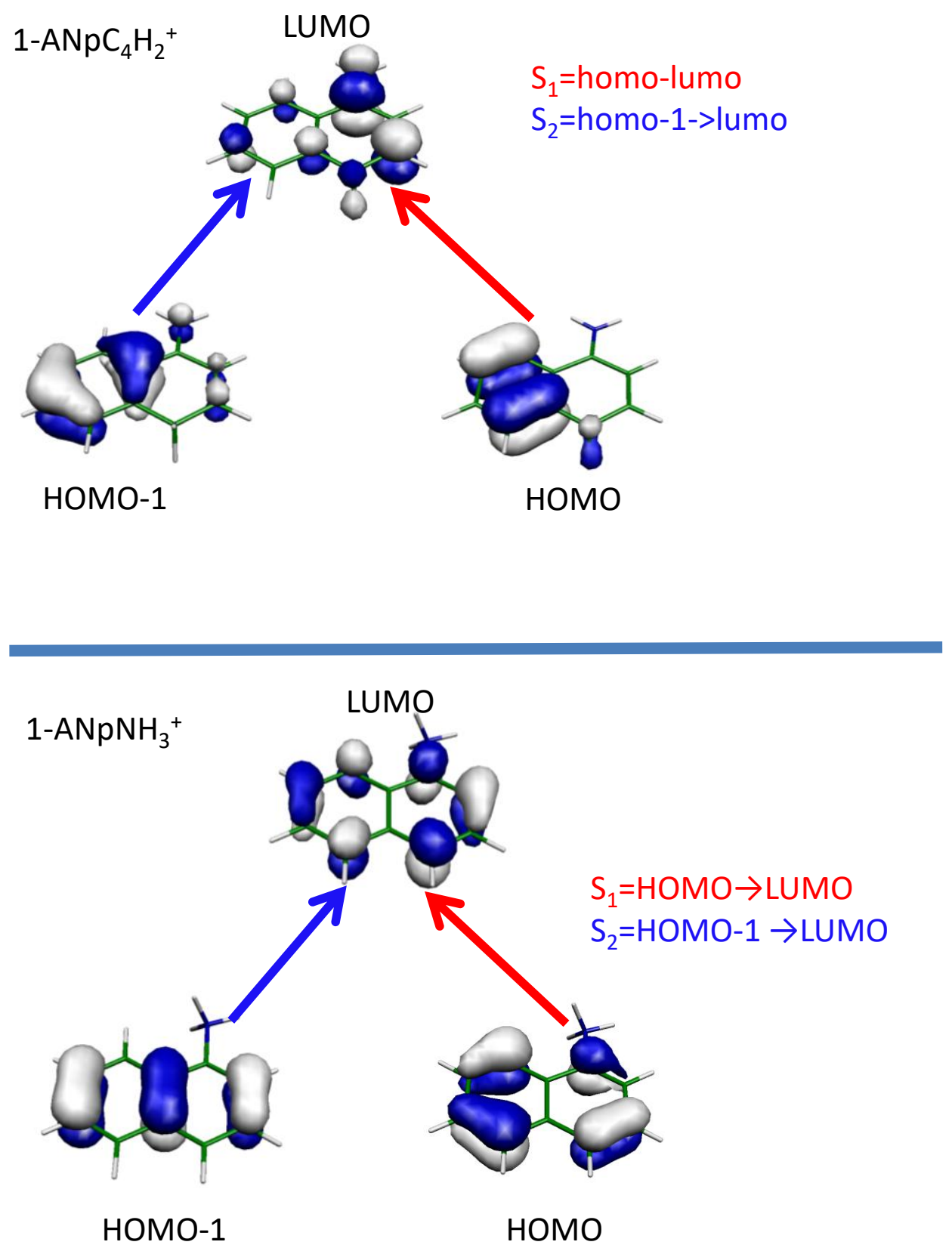
Figure SI-7: orbitals involved in the two first electronic transitions in the 2- $\mathrm{ANpC}_{1} \mathrm{H}_{2}{ }^{+}$and 2ANpNH ${ }_{3}{ }^{+}$tautomers.
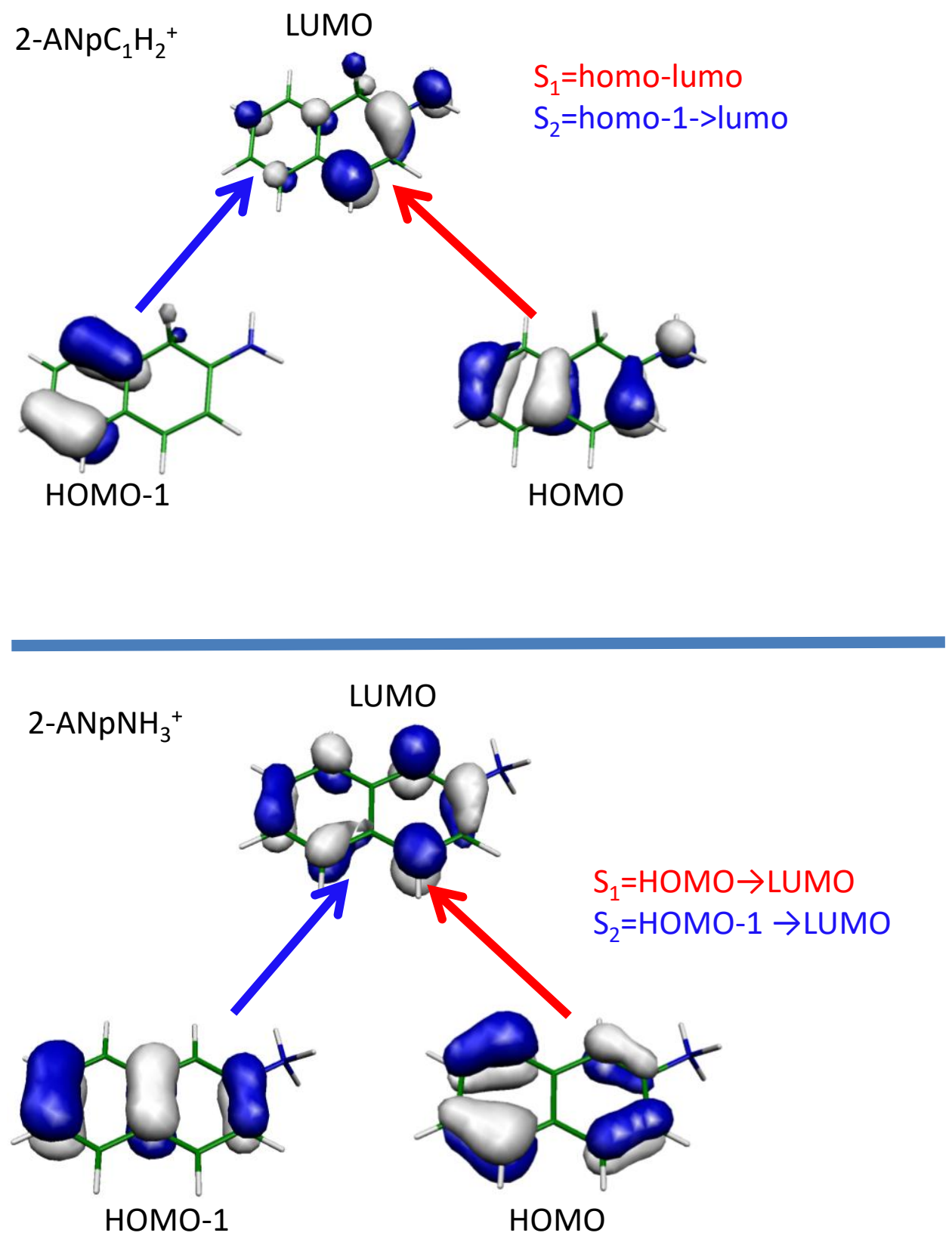


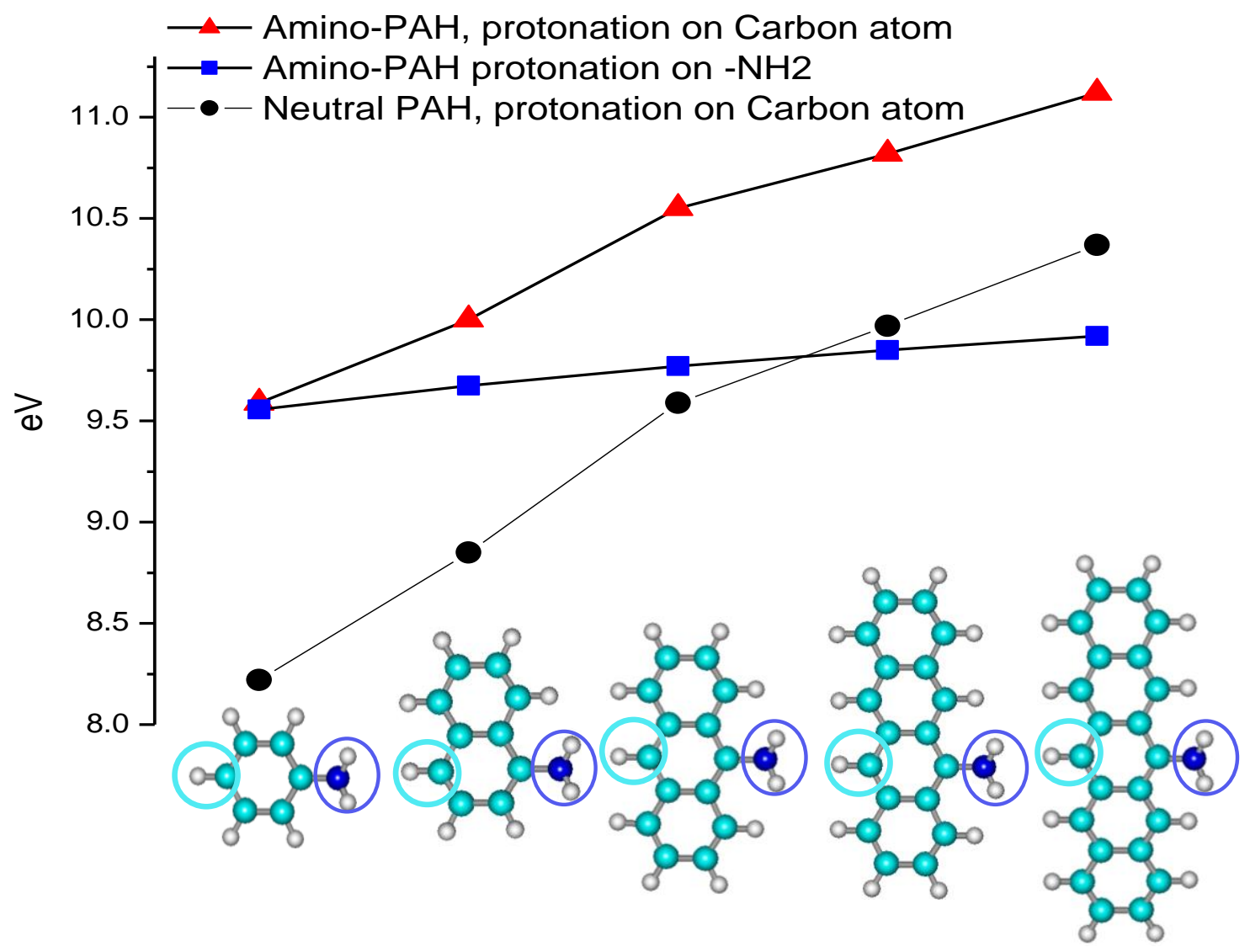

Figure SI-8: Evolution of proton affinities (PA) with molecular size; compared to the data presented in figure 6 in the manuscript, the PA of protonated unsubstituted PAH (black circles) has been added. For homogeneity, the PA values of neutral PAHs reported in this figure have been calculated using the same method as for the amino aromatic molecules, DFT/B3LYP/cc-pVDZ.: 
Table SI-1: Relative ground state energies calculated at different levels of theory for different 1- and 2$A N p H^{+}$tautomers (cc-pVDZ basis set). The energies are relative to the ground state energy of the 1$\mathrm{ANpNH}_{3}{ }^{+}$or 2-ANpNH ${ }_{3}{ }^{+}$tautomer. All energies are in eV (cm ${ }^{-1}$, in parenthesis). We report all eV values to the nearest $0.01 \mathrm{eV}$ and all wavenumber values to the nearest $5 \mathrm{~cm}^{-1}$.

\begin{tabular}{|c|c|c|c|c|c|c|c|c|}
\hline & 1-ANpNH ${ }_{3}^{+}$ & 1-ANpC ${ }_{2} \mathrm{H}_{2}^{+}$ & 1- $\mathrm{ANpC}_{3} \mathrm{H}_{2}^{+}$ & 1- $\mathrm{ANpC}_{4} \mathrm{H}_{2}^{+}$ & 1- $\mathrm{ANpC}_{5} \mathrm{H}_{2}^{+}$ & 1- $\mathrm{ANpC}_{6} \mathrm{H}_{2}^{+}$ & $1-\mathrm{ANpC}_{7} \mathrm{H}_{2}^{+}$ & 1- $\mathrm{ANpC}_{8} \mathrm{H}_{2}^{+}$ \\
\hline DFT & $\begin{array}{l}0 \\
0\end{array}$ & $\begin{array}{c}-0.14 \\
(-1130)\end{array}$ & $\begin{array}{c}+0.80 \\
(+6450)\end{array}$ & $\begin{array}{c}-0.33 \\
(-2660)\end{array}$ & $\begin{array}{c}+0.39 \\
(+3150)\end{array}$ & $\begin{array}{c}+0.80 \\
(+6450)\end{array}$ & $\begin{array}{c}+0.42 \\
(+3390)\end{array}$ & $\begin{array}{c}+0.62 \\
(+5000)\end{array}$ \\
\hline $\mathrm{CC} 2$ & 0 & +0.07 & & -0.12 & & & & \\
\hline $\operatorname{CCSD}(T)$ & 0 & $\begin{array}{l}-0.032 \\
(-255)\end{array}$ & & $\begin{array}{c}-0.21 \\
(-1715)\end{array}$ & & & & \\
\hline MP2 & 0 & +0.17 & & -0.01 & & & & \\
\hline MP4 & 0 & $\begin{array}{l}0.009 \\
(+75)\end{array}$ & & $\begin{array}{c}-0.17 \\
(-1360)\end{array}$ & & & & \\
\hline
\end{tabular}

\begin{tabular}{|c|c|c|c|c|c|c|c|c|}
\hline & 2- $\mathrm{ANpNH}_{3}{ }^{+}$ & 2-ANpC ${ }_{1} \mathrm{H}_{2}^{+}$ & 2-ANpC ${ }_{3} \mathrm{H}_{2}^{+}$ & 2-ANpC ${ }_{4} \mathrm{H}_{2}^{+}$ & $2-\mathrm{ANpC}_{5} \mathrm{H}_{2}^{+}$ & 2-ANpC ${ }_{6} \mathrm{H}_{2}^{+}$ & $2-\mathrm{ANpC}_{7} \mathrm{H}_{2}^{+}$ & $2-\mathrm{ANpC}_{8} \mathrm{H}_{2}^{+}$ \\
\hline DFT & $\begin{array}{l}0 \\
0\end{array}$ & $\begin{array}{c}-0.31 \\
(-2500)\end{array}$ & $\begin{array}{c}+0.28 \\
(+2260)\end{array}$ & $\begin{array}{c}0.67 \\
(+5400) \\
\end{array}$ & $\begin{array}{c}+0.57 \\
(+4600)\end{array}$ & $\begin{array}{c}+0.07 \\
(+565)\end{array}$ & $\begin{array}{c}+0.68 \\
(+5480)\end{array}$ & $\begin{array}{l}+0.06 \\
(+485)\end{array}$ \\
\hline $\mathrm{CC} 2$ & 0 & -0.09 & & & & +0.37 & +1.04 & +0.36 \\
\hline $\operatorname{CCSD}(\mathrm{T})$ & 0 & $\begin{array}{c}-0.14 \\
(-1170) \\
\end{array}$ & & & & $\begin{array}{c}+0.26 \\
(+2060) \\
\end{array}$ & & $\begin{array}{c}+0.29 \\
(+2370) \\
\end{array}$ \\
\hline MP2 & 0 & +0.03 & & & & +0.57 & +1.11 & +0.57 \\
\hline MP4 & 0 & $\begin{array}{l}-0.11 \\
(-865)\end{array}$ & & & & $\begin{array}{c}+0.32 \\
(+2555)\end{array}$ & & $\begin{array}{c}+0.35 \\
(+2815)\end{array}$ \\
\hline
\end{tabular}

As seen above, the 1-ANpC $\mathrm{H}_{2}{ }^{+}$tautomer is always found to be more stable than the 1$\mathrm{ANpNH}_{3}{ }^{+}$tautomer. The $1-\mathrm{ANpC}_{2} \mathrm{H}_{2}{ }^{+}$is more stable than $1-\mathrm{ANpNH}_{3}{ }^{+}$with DFT and almost isoenergetic with 1-ANpNH${ }_{3}^{+}$using $\mathrm{CCSD}(\mathrm{T})$ or MP4 methods. For 2-ANpH ${ }^{+}$, the 2- $\mathrm{ANpC}_{1} \mathrm{H}_{2}{ }^{+}$ tautomer is more stable than the $2-\mathrm{ANpNH}_{3}{ }^{+}$tautomer, while the $2-\mathrm{ANpC}_{6} \mathrm{H}_{2}{ }^{+}$and $2-\mathrm{ANpC}_{8} \mathrm{H}_{2}{ }^{+}$ tautomers are always less stable than the $2-\mathrm{ANpNH}_{3}{ }^{+}$tautomer. As already noted in previous reports ${ }^{1}$, the MP2 (see table SI-1) method overestimates the stability of the $\mathrm{NH}_{3}{ }^{+}$tautomer compared to the $\mathrm{C}_{\mathrm{n}} \mathrm{H}_{2}{ }^{+}$tautomers, while DFT, MP4 and $\operatorname{CCSD}(T)$ methods provide consistent results. 
Table SI-2: Calculated frequencies at the CC2/aug-cc-pVDZ level of the first excited state of 1$\mathrm{ANpNH}_{3}{ }^{+}$and tentative assignments of the bands observed

\begin{tabular}{|c|c|c|c|c|}
\hline $\begin{array}{r}\text { Mode } \\
\text { number }\end{array}$ & $\begin{array}{c}\text { Calculated } \\
\text { frequencies }\end{array}$ & & $\begin{array}{c}\text { Observed } \\
\text { frequencies }\end{array}$ & $\begin{array}{c}\text { tentative } \\
\text { assignment }\end{array}$ \\
\hline 1 & 80 & $\mathrm{NH}_{3}$ rotation & & \\
\hline 2 & 136 & $\mathrm{NH}_{3}$ rotation & & \\
\hline \multirow[t]{2}{*}{3} & 152 & Ring deformation out of plane & & \\
\hline & & & $159(2 * 80)$ & $1_{0}^{2}$ \\
\hline 4 & 163 & Ring deformation out of plane & & \\
\hline 5 & 249 & $\mathrm{NH}_{3}$ bending in plane & & \\
\hline 6 & 302 & Ring deformation out of plane & & \\
\hline 7 & 354 & Ring deformation out of plane & & \\
\hline 8 & 379 & Ring deformation in plane & 419 & $8_{0}^{1}$ \\
\hline 9 & 404 & Ring deformation out of plane & & \\
\hline 10 & 420 & Ring deformation out of plane & & \\
\hline 11 & 424 & Ring deformation in plane & 482 & ${ }^{11} 1_{0}^{1}$ \\
\hline 12 & 463 & Ring deformation in plane & & \\
\hline 13 & 527 & Ring deformation in plane & 538 & $13_{0}^{1}$ \\
\hline 14 & 531 & $\mathrm{C}_{2} \mathrm{H}$ out of plane & & \\
\hline 15 & 583 & Ring deformation out of plane & & \\
\hline 16 & 633 & Ring breathing in plane & 658 & $16_{0}^{1}$ \\
\hline 17 & 684 & $\mathrm{CH}$ out of plane & & \\
\hline 18 & 736 & $\mathrm{CH}$ out of plane & & \\
\hline 19 & 752 & $\mathrm{CH}$ out of plane & & \\
\hline 20 & 755 & Ring deformation in plane & & \\
\hline 21 & 817 & Ring in plane & 830 & ${ }^{21}{ }_{0}^{1}$ \\
\hline 22 & 832 & $\mathrm{CH}$ out of plane & & \\
\hline 23 & 853 & $\mathrm{CH}$ out of plane & & \\
\hline 24 & 874 & $\mathrm{CH}$ out of plane & & \\
\hline \multirow[t]{3}{*}{25} & 907 & Ring deformation in plane & & \\
\hline & & & 914 & $8_{0}^{1} 13_{0}^{1}$ \\
\hline & & & 978 & ${ }^{11_{0}^{1}}{ }^{13}{ }_{0}^{1}$ \\
\hline \multirow[t]{2}{*}{26} & 992 & ring in plane & & \\
\hline & & & 1017 & $8_{0}^{1} 16_{0}^{1}$ \\
\hline 27 & 1025 & $\mathrm{NH} / \mathrm{CH}$ in plane & & \\
\hline
\end{tabular}




\begin{tabular}{|c|c|c|c|c|}
\hline 28 & 1040 & $\mathrm{NH}_{3}$ out of plane & & \\
\hline 29 & 1044 & $\mathrm{NH} \& \mathrm{CH}$ bend in plane & & \\
\hline 30 & 1108 & $\mathrm{CH}$ bend in plane & & \\
\hline 31 & 1137 & $\mathrm{CH}$ bend in plane & & \\
\hline \multirow[t]{3}{*}{32} & 1150 & $\mathrm{CH}$ bend in plane & & \\
\hline & & & 1160 & ${ }^{13}{ }_{0}^{1} 16_{0}^{1}$ \\
\hline & & & 1196 & \\
\hline \multirow[t]{2}{*}{33} & 1207 & $\mathrm{CH}$ bend in plane & & \\
\hline & & & 1219 & ${ }^{8} 0^{1} 21_{0}^{1}$ \\
\hline 34 & 1228 & $\mathrm{CH}$ bend in plane & & \\
\hline 35 & 1242 & $\mathrm{CH}$ bend in plane & & \\
\hline \multirow[t]{2}{*}{36} & 1344 & $\mathrm{CH}$ bend in plane & & \\
\hline & & & 1351 & \\
\hline \multirow[t]{2}{*}{37} & 1384 & $\mathrm{CH}$ bend in plane & & \\
\hline & & & 1390 & \\
\hline 38 & 1408 & $\mathrm{CH}$ bend in plane & & \\
\hline 39 & 1427 & $\mathrm{CH}$ bend in plane $\& \mathrm{NH}_{3}$ umbrella & & \\
\hline \multirow[t]{2}{*}{40} & 1444 & $\mathrm{CH}$ bend in plane \& ring deformation & & \\
\hline & & & 1450 & \\
\hline 41 & 1470 & Ring deformation in plane \& $\mathrm{NH}_{3}$ umbrella & & \\
\hline 42 & 1479 & $\mathrm{NH}_{3}$ umbrella & & \\
\hline \multirow[t]{3}{*}{43} & 1489 & Ring deformation in plane & & \\
\hline & & & 1497 & \\
\hline & & & 1550 & \\
\hline 44 & 1618 & $\mathrm{NH}_{3}$ antisymmetric bend & & \\
\hline 45 & 1618 & NH symmetric +ring deformation in plane & & \\
\hline 46 & 1632 & $\mathrm{NH}$ symmetric bend & & \\
\hline 47 & 1659 & NH symmetric +ring deformation in plane & & \\
\hline 48 & 3171 & $\mathrm{CH}$ stretch & & \\
\hline 49 & 3202 & $\mathrm{CH}$ stretch & & \\
\hline 50 & 3204 & $\mathrm{CH}$ stretch & & \\
\hline 51 & 3208 & $\mathrm{CH}$ stretch & & \\
\hline 52 & 3217 & $\mathrm{CH}$ stretch & & \\
\hline 53 & 3230 & $\mathrm{CH}$ stretch & & \\
\hline 54 & 3242 & $\mathrm{CH}$ stretch & & \\
\hline 55 & 3335 & $\mathrm{NH}_{3}$ stretch symmetric & & \\
\hline 56 & 3413 & $\mathrm{NH}_{3}$ stretch antisymmetric & & \\
\hline 57 & 3479 & $\mathrm{NH}_{3}$ stretch antisymmetric & & \\
\hline
\end{tabular}


Table SI-3: Comparison of the calculated tautomer stability for ions isolated in the gas phase or ions in solution calculated using COSMO (COnductor-like Screening Model) as implemented in the Turbomole package. The calculations indicate that the tautomer protonated on the amino group is the most stable in solution, whereas protonation on a carbon atom ( $\mathrm{C} 4$ for $1-\mathrm{ANpH}^{+}$and $\mathrm{C} 1$ for $\left.2-\mathrm{ANpH}^{+}\right)$is favored for isolated molecules.

\begin{tabular}{|l|l|l|}
\hline & DFT & $\begin{array}{r}\text { DFT+COSMO } \\
(\varepsilon=80)\end{array}$ \\
\hline $1-\mathrm{ANpNH}_{3}{ }^{+}$ & 0 & 0 \\
\hline $1-\mathrm{ANpC}_{2} \mathrm{H}_{2}{ }^{+}$ & -0.14 & +0.35 \\
\hline $1-\mathrm{ANpC}_{4} \mathrm{H}_{2}{ }^{+}$ & -0.33 & +0.22 \\
\hline \hline $2-\mathrm{ANpNH}_{3}{ }^{+}$ & 0 & 0 \\
\hline $2-\mathrm{ANpC}_{1} \mathrm{H}_{2}{ }^{+}$ & -0.31 & +0.24 \\
\hline
\end{tabular}




\section{Energetics of the dissociation channels}

The energetics of the dissociation channels has been calculated at the DFT level and is summarized in figure 5 together with the energy of the observed excited states. (The details of the calculations can be found in the table SI-4)

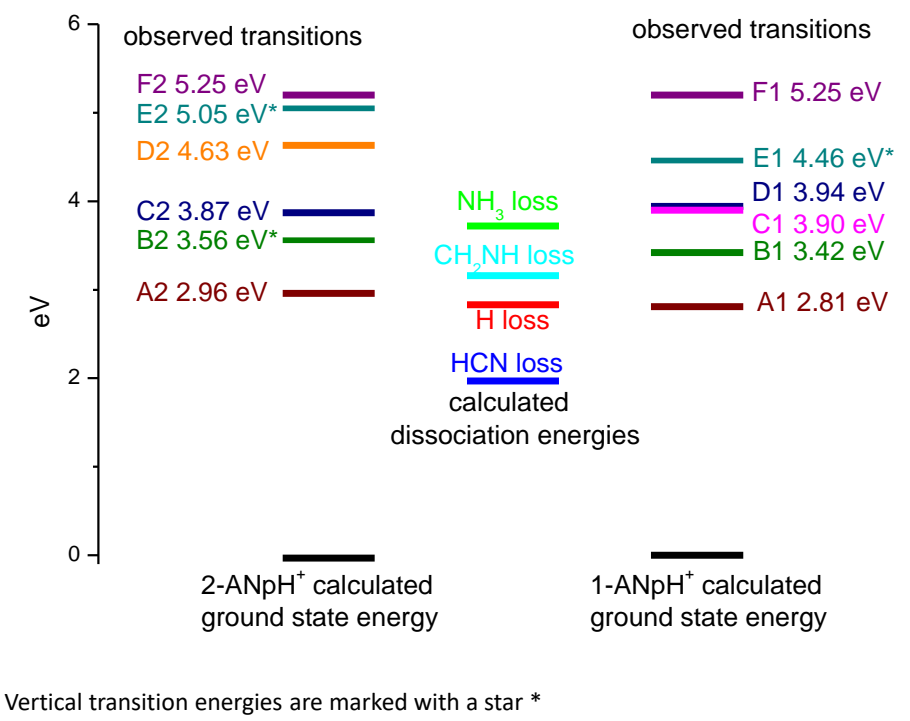

Figure 5: Comparison between the energy of the electronic transitions and the energy of the dissociation channels.

The lower dissociation energy corresponds to the HCN loss channel, well below the energy of the first band system, while the $\mathrm{NH}_{3}$ loss channel has the highest dissociation energy, slightly lower than the energy of the most intense band system D1 and C2. It should be noted that the $\mathrm{H}$ loss channel as well as the $\mathrm{NH}_{3}$ loss channel are simple bond cleavage for aminonaphthalene protonated on the amino group. On the other hand, the other dissociation channels necessitate rearrangement processes involving barriers higher than the dissociation energy. As in protonated aminopyrene ${ }^{1}$, the $\mathrm{NH}_{3}$ loss channel is higher in energy than the $\mathrm{H}$ loss channel by almost $1 \mathrm{eV}$.

Note that the HCN loss channel is observed for the low energy band systems (A1, B1 and A2), but absent when exciting the D1 and C2 major band systems. In protonated diazine and aminopyridine $\mathrm{e}^{2,3}$, the HCN loss channel mechanism involves a hydrogen or proton transfer to a carbon atom, and if the same mechanism is assumed for $\mathrm{ANpH}^{+}$, the most probable parents will 
be the $\mathrm{ANpC}_{\mathrm{n}} \mathrm{H}_{2}{ }^{+}$tautomers. This would therefore mean that the $\mathrm{D} 1$ and $\mathrm{C} 2$ band systems correspond to 1-and 2-ANpNH${ }_{3}{ }^{+}$tautomers. These assumptions may be checked by comparison with calculations of the excited state transitions.

Table SI-4: Energetics of the dissociation channels

\begin{tabular}{|c|c|c|c|c|c|}
\hline & $\begin{array}{c}\text { Energy } \\
\text { DFT/B3lyp } \\
\text { (hartree) }\end{array}$ & \multicolumn{2}{|c|}{$\begin{array}{l}\text { Proton affinity } \\
\text { (eV) }\end{array}$} & $\begin{array}{c}\text { Energy } \\
\text { DFT/B3lyp } \\
\text { (hartree) }\end{array}$ & \\
\hline $\begin{array}{l}1 \text {-ANp } \\
\text { mass } 143\end{array}$ & -440.9942406 & & & -440.99413893 & $\begin{array}{l}2 \text {-ANp } \\
\text { mass } 143\end{array}$ \\
\hline $\begin{array}{l}\text { 1-ANpH } \\
\mathrm{m} / \mathrm{z} 144\end{array}$ & -441.3497544 & 9.67 & 9.71 & -441.35092526 & $\begin{array}{l}\text { 2-ANpH } \\
\mathrm{m} / \mathrm{z} 144\end{array}$ \\
\hline & & \multicolumn{2}{|c|}{$\begin{array}{c}\text { Dissociation } \\
\text { Energy (eV) }\end{array}$} & & \\
\hline $\begin{array}{l}\text { HCN loss channel } \\
\mathrm{m} / \mathrm{z} 117+27(\mathrm{HCN})\end{array}$ & $\begin{array}{l}-347.899-93.378 \\
=-441.277\end{array}$ & 1.97 & 2.00 & $\begin{array}{l}-347.899-93.378 \\
=-441.277\end{array}$ & $\begin{array}{l}\text { HCN loss channel } \\
\mathrm{m} / \mathrm{z} 117+27(\mathrm{HCN})\end{array}$ \\
\hline $\begin{array}{l}\text { H loss channel } \\
m / z 143\left(1-\mathrm{ANp}^{+}\right)+1 \\
\text { (H) }\end{array}$ & $\begin{array}{l}-440.7476-0.4983 \\
=-441.2459\end{array}$ & 2.83 & 2.87 & $\begin{array}{l}-440.7472-0.4983 \\
=-441.2455\end{array}$ & $\begin{array}{l}\text { H loss channel } \\
\mathrm{m} / \mathrm{z} 143\left(2-\mathrm{ANp}^{+}\right)+1 \\
\text { (H) }\end{array}$ \\
\hline $\begin{array}{l}\mathrm{CH}_{2} \mathrm{NH} \text { loss channel } \\
\mathrm{m} / \mathrm{z} 115+29\left(\mathrm{CH}_{2} \mathrm{NH}\right)\end{array}$ & $\begin{array}{l}-346.659-94.574 \\
=-441.233\end{array}$ & 3.16 & 3.19 & $\begin{array}{l}-346.659-94.574 \\
=-441.233\end{array}$ & $\begin{array}{l}\mathrm{CH}_{2} \mathrm{NH} \text { loss channel } \\
\mathrm{m} / \mathrm{z} 115+29\left(\mathrm{CH}_{2} \mathrm{NH}\right)\end{array}$ \\
\hline $\begin{array}{l}\mathrm{NH}_{3} \text { loss channel } \\
\mathrm{m} / \mathrm{z} 127+17\left(\mathrm{NH}_{3}\right)\end{array}$ & $\begin{array}{l}-384.695-56.518 \\
=-441.213\end{array}$ & 3.72 & 3.84 & $\begin{array}{l}-384.692-56.518 \\
=-441.210\end{array}$ & $\begin{array}{l}\mathrm{NH}_{3} \text { loss channel } \\
\mathrm{m} / \mathrm{z} 127+17\left(\mathrm{NH}_{3}\right)\end{array}$ \\
\hline
\end{tabular}

\section{References}

(1) Noble, J. A.; Dedonder-Lardeux, C.; Mascetti, J.; Jouvet, C. Electronic Spectroscopy of Protonated 1-Aminopyrene in a Cold Ion Trap. Chem. - An Asian J. 2017, 125, 1523-1531. 